\title{
A Theory of Divided Government
}

\section{Citation}

Alesina, Alberto, and Howard Rosenthal. 1996. "A Theory of Divided Government." Econometrica 64 (6) (November): 1311. doi:10.2307/2171833.

\section{Published Version}

doi:10.2307/2171833

\section{Permanent link}

http://nrs.harvard.edu/urn-3:HUL.InstRepos:34222831

\section{Terms of Use}

This article was downloaded from Harvard University's DASH repository, and is made available under the terms and conditions applicable to Other Posted Material, as set forth at http:// nrs.harvard.edu/urn-3:HUL.InstRepos:dash.current.terms-of-use\#LAA

\section{Share Your Story}

The Harvard community has made this article openly available.

Please share how this access benefits you. Submit a story.

Accessibility 


\title{
A THEORY OF DIVIDED GOVERNMENT ${ }^{1}$
}

\author{
By Alberto Alesina ANd Howard Rosenthal
}

\begin{abstract}
This paper extends the spatial theory of voting to an institutional structure in which policy choices depend upon not only the executive but also the composition of the legislature. Voters have incentives to be strategic since policy reflects the outcome of a simultaneous election of the legislature and the executive and since the legislature's impact on policy depends upon relative plurality. To analyze equilibrium in this game between voters, we apply "coalition proof" type refinements. The model has several testable implications which are consistent with voting behavior in the United States. For instance, the model predicts: (a) split-tickets where some voters vote for one party for president and the other for congress; (b) for some parameter values, a divided government with different parties controlling the executive and the majority of the legislature; and (c) the midterm electoral cycle with the party holding the presidency always losing votes in midterm congressional elections.
\end{abstract}

KEYwORDS: Voting theory, checks and balances, conditional sincerity, midterm cycle, coalition proof Nash equilibria.

\section{INTRODUCTION}

NATIONAL POLICIES TYPICALlY REFLECT the composition of both the executive and the legislature. In the United States, for instance, the administration's influence on policy is affected by the composition of congress.

Traditional spatial models of elections ignore this institutional complexity and assume that the winner of a two-party race fully controls policy. ${ }^{2}$ These models focus on the strategic interaction between the candidates and treat each voter as a passive player, voting for the candidate offering the more preferred policy.

In our model, instead, the voters face two parties with preferences defined on policy outcomes (Wittman (1977, 1990), Calvert (1985), Alesina (1988)). Without "checks" by the legislature, the executives representing the two parties pursue distinct and polarized policies. ${ }^{3}$ However, policy outcomes in our model are a function not only of which party holds the executive but also of the composition of the legislature.

The ideal policies of the two parties are identified by two points on an interval; voters to the left of the left party's policy always vote for this party in both the legislative and presidential elections; similarly, voters on the right of

\footnotetext{
${ }^{1}$ This work was supported by National Sciẹnce Foundation Grant SES-8821441. Alesina also gratefully acknowledges support from the Sloan Foundation. An earlier version of this paper was circulated with the title "Moderating Elections." We thank Geir Asheim, Michael Whinston, a co-editor, and the referees for extremely helpful comments. The manuscript was revised while Rosenthal was a fellow of the Center for Advanced Study in the Behavioral Sciences.

${ }^{2}$ For example, see Kramer (1973). For surveys of this literature, see Enelow and Hinich (1984) and Ordeshook (1986).

${ }^{3}$ The existence of "polarization" in American politics has been widely documented by Poole and Rosenthal (1984a, b; 1991).
} 
the right party have a dominant strategy to vote for the right party. In contrast, voters with ideal policies intermediate between the positions of the parties take advantage of the institutional structure of "checks and balances" to moderate the executive and achieve a policy outcome closer to their ideal. This realistic feature of the model implies strategic voting. Unlike the traditional spatial model, the decision of each "middle-of-the-road" voter depends upon his beliefs about the behavior of other voters. Thus we examine strategic voting in the context of the "new institutionalism's" concern about the executive-legislative interaction (Shepsle (1986), Hammond and Miller (1988), Fiorina $(1990,1991)){ }^{4}$

Our model of "moderating behavior" has implications consistent with three observations concerning American politics: split-ticket voting, the midterm cycle, and divided government. The model predicts split-ticket voting when the executive and the legislature are elected simultaneously. That is, some voters support different parties in the two elections to, say, counterbalance a president on the right with a legislature on the left. The model also captures the persistent phenomenon of the "midterm voting cycle." In midterm congressional elections, the president's party loses plurality relative to the preceding congressional elections held simultaneously with the presidential election. Our explanation relies upon the fact that in presidential election years the electorate faces uncertainty about who will win the presidency. Moderate voters want neither a left-dominated congress for fear that the president may turn out to be left, nor a right-dominated congress lest the president be right. Their uncertainty about the outcome of the presidential election leads them to prefer a "hedged" congress. At midterm, once the identity of the president is known, voters move congress further in the direction opposite to that of the president in order to achieve better moderation. Empirical studies by Alesina and Rosenthal (1989), Erikson (1990), and Alesina, Londregan, and Rosenthal (1993) have shown that this model of the midterm effect performs at least as well and often better than traditional empirical voting models that emphasize incumbency advantage and retrospective voting based on the state of the economy. ${ }^{5}$ A sufficiently strong midterm cycle or substantial split-ticket voting will produce divided government where the party holding the presidency does not have a majority in the legislature.

We present both a complete information and an incomplete information model. In the former, but not the latter, the distribution of voter ideal points is common knowledge. Split-ticket voting, moderating behavior, and divided gov-

\footnotetext{
${ }^{4}$ Cox (1987) analyzes strategic voting when voters decide more than one contest in the context of the double-member districts of Victorian England. He finds evidence of substantial split-ticket voting until cabinet government is instituted. With cabinet government, policy depends only on a parliamentary majority and not on, as in the American system, an executive-legislative interaction that is affected by the composition of the legislature. The virtual disappearance of split-ticket voting under cabinet government is expected from the perspective of our model.

${ }^{5}$ Erikson (1988) tests coattails and other alternative explanations of the midterm cycle and finds that they are not supported by the data.
} 
ernment, present in both cases, can be more easily illustrated with the complete information model. ${ }^{6} \mathrm{~A}$ midterm cycle emerges only in the incomplete information model. The Alesina and Rosenthal (1995, pp. 43-120) volume, written after the initial draft of this paper, motivates these models using the concept of conditional sincerity briefly discussed in Section 3.2 of this paper but does not analyze equilibrium using the game-theoretic concepts of abstract stable sets and coalition proof Nash equilibrium.

The paper is organized as follows. In Section 2 we describe the one-period model and the game-theoretic solution concepts which we employ. We analyze equilibrium in this basic model in Section 3. This section uses rather general assumptions about functional forms. In Section 4 we present the two-period complete information case with more restrictive assumptions. In Section 5 we discuss the incomplete information version of the model for specific functional forms. Section 6 concludes.

\section{THE ONE-PERIOD MODEL}

\subsection{Preferences and Institutional Setup}

We consider a two-party system in which the parties (identified with the candidates) have policy preferences. In particular, the two parties, labelled $D$ and $R$, and the voters have unidimensional, continuous, and strictly concave utility functions over a single policy issue. Utility functions are all identical except for the bliss point. The utility of a policy $x$ is given as

$$
u_{i}=u\left(x, \theta_{i}\right)
$$

where, for the two parties, we denote the bliss points as $\theta_{D}$ and $\theta_{R}$ with $0 \leq \theta_{D}<\theta_{R} \leq 1$ and, for the generic voter $i$, we denote the bliss point as $\theta_{i}$. There is a continuum of voters. The bliss point cumulative distribution $H(\theta)$ is continuous and strictly increasing on the interval $I=[0,1]$. The median type is denoted $\mu=H^{-1}(0.5)$. Any non-null subset, $S$, of $I$ is termed a coalition. The preferences of both parties and voters are common knowledge. We choose to work with a continuum of voters rather than with a finite number for reasons of technical convenience clarified in footnote 13, following Proposition 2 below.

The president is elected by majority vote. If the executive had complete control of policy, the party winning the presidency would adopt its ideal policy

\footnotetext{
${ }^{6}$ Fiorina (1988) proposed a model of split-ticket voting which is related to ours; however there are three important differences between the models. Fiorina's specification allows for only four policy outcomes, corresponding to the four combinations of parties holding the executive and the majority in the legislature, while we allow for a continuum of policies. Second, and more importantly, Fiorina does not consider strategic voting. Third, since Fiorina's model has only one period, he does not address the midterm cycle.
} 
$\left(\theta_{D}\right.$ or $\left.\theta_{R}\right) .^{7}$ However, the institutional structure of our model posits that policy is determined by a compromise between the president and the legislature, which is elected by strict proportional representation in a single national district.

Let us define $V_{j}, j=D, R$, to be the proportion of votes obtained by party $j$ in the legislative elections. Since we assume full turnout, $V_{R}=1-V_{D}$. The policies, $x^{D}$ and $x^{R}$, that result when $D$ and $R$, respectively, hold the presidency, are given by

$$
\begin{aligned}
& x^{D}=\theta_{D}+g_{D}\left(V_{R}\right), \\
& x^{R}=\theta_{R}-g_{R}\left(1-V_{R}\right),
\end{aligned}
$$

where $g_{j}(\cdot), j \in\{D, R\}$, is continuous, strictly increasing in its argument with $g_{j}(0)=0$, and is common knowledge. Equations (2) and (3) capture the idea that policy outcomes are further from the president's ideal policy the greater the opposition's share in the legislature. Since the functions $g_{j}(\cdot)$ can be nonlinear, they can be very "steep" at $V_{R}=\frac{1}{2}$, that is at the point where the majority in the legislature changes hands. ${ }^{8}$ We assume

$$
\theta_{D}+g_{D}\left(V_{R}\right)<\theta_{R}-g_{R}\left(1-V_{R}\right)
$$

which implies that, for $V_{R}$ fixed,

$$
\theta_{D}<x^{D}<x^{R}<\theta_{R}
$$

Condition (5) states that, realistically, for a given level of the legislative vote, policy is always more "left" when $D$ is president than when $R$ is president.

We now specify a one-period game in which both the president and the legislature are elected simultaneously. In Section 4 we extend the model to a two-period case in which the president serves for two periods while the legislature is elected every period.

\subsection{The Game}

Each voter $i$ chooses strategy $z_{i}$ specified as a pair $z_{i}^{1} z_{i}^{2} \in Z^{i} \equiv$ $\{D D, D R, R D, R R\}$, where $z_{i}^{1}$ refers to the presidential election and $z_{i}^{2}$ to the legislative. We treat only pure strategies in the text. In the Appendix, we show that this restriction is inconsequential. Let $Z^{I}$ be the Cartesian product of the $Z^{i}$ and $z=z^{1} z^{2}$ be an element of $Z^{I}$. Without loss of generality, we limit

\footnotetext{
${ }^{7}$ In a two party regime without institutional checks and balances, this is the one-shot equilibrium to the electoral game described in Alesina (1988). In fact, no other policy announced prior to elections would be implemented by the elected party, given that the party can choose its ideal policy when in office. Thus, rational voters would not believe in any announcement other than the party ideal policy.

${ }^{8}$ In fact, all our complete information results hold in the discontinuous, majoritarian setup of Fiorina (1988) described in footnote 6. (See Alesina and Rosenthal (1995, pp. 66-71).) We feel, however, that the continuous model is more realistic, especially for the United States, where the filibuster and other features of the legislative landscape enhance the power of minorities.
} 
attention to measurable strategy constellations $z$. Consequently, $M_{R z} \equiv$ $\sigma\left(\left\{i: i \in I\right.\right.$ and $\left.\left.z_{i}^{1}=R\right\}\right)$ and $V_{R z} \equiv \sigma\left(\left\{i: i \in I\right.\right.$ and $\left.\left.z_{i}^{2}=R\right\}\right)$ are well defined, where $\sigma(S)$ denotes the Lebesque measure of a set $S$. Let $P_{z}\left(M_{R z}\right)$ denote the probability, specified by the electoral law, that $R$ is president:

$$
\begin{aligned}
& \text { If } m_{R z}>\frac{1}{2}, P_{z}=1 \text { (majority for } R \text { president), } \\
& \text { if } M_{R z}<\frac{1}{2}, P_{z}=0 \text { (majority for } D \text { president), } \\
& \text { if } M_{R z}=\frac{1}{2}, P_{z}=P, 0 \leq P \leq 1 \text { (tied presidential vote). }
\end{aligned}
$$

This specification allows for different tie-breaking rules, including the toss of a fair coin.

For simplicity, in the remainder of the text, we assume $R$ wins the presidency if the vote is tied; that is, $P=1$ if $M_{R z}=\frac{1}{2} \cdot{ }^{9}$ If $0<P<1$ when $M_{R z}=\frac{1}{2}$, our results also go through. (The proof, in Alesina and Rosenthal (1993), the working paper version of this paper, is available upon request.) We define the indicator variable $J_{z}$ by

$$
\begin{aligned}
& J_{z}=D \quad \text { if } \quad M_{R z}<\frac{1}{2}, \\
& J_{z}=R \quad \text { if } \quad M_{R z} \geq \frac{1}{2} .
\end{aligned}
$$

For any $z$, the policy outcomes can be determined by substituting $V_{R z}$ for $V_{R}$ in (2) or (3). Utilities are then determined by (1).

While our analysis allows for all measurable $z$, it is useful to define "cutpoint" strategies.

DEFINITION: If there exists $\theta$ such that voters in a coalition $S$ with $\theta_{i}<\theta$ vote $D$ and voters with $\theta_{i}>\theta$ vote $R$ in an electoral contest, $\theta$ is called a cutpoint on $S$ (of $z$ ) for the contest. ${ }^{10}$ If a strategy constellation $z$ can be represented by both a presidential cutpoint on $S$, denoted $\hat{\theta}$, and a legislative cutpoint on $S$, denoted $\tilde{\theta}, z$ is a cutpoint strategy on $S$.

For brevity, when $S=I$, we refer to $z$ simply as a "cutpoint strategy." A cutpoint strategy has at most three types of voters. For instance, if $\hat{\theta}<\tilde{\theta}$, we have $D D$ voters who have ideal points below $\hat{\theta}, R D$ voters who have ideal points between $\hat{\theta}$ and $\tilde{\theta}$, and $R R$ voters who have ideal points above $\tilde{\theta}$.

\footnotetext{
${ }^{9}$ By symmetry, nothing changes when a tie goes to $D$.

${ }^{10}$ The voter type $\theta_{t}=\theta$ is uninfluential because of zero measure.
} 


\subsection{The Need for a Refinement}

We must apply a refinement of the Nash concept to our game to address three problems engendered by our model.

The first problem arises from our institutional structure incorporating simultaneous election of the executive and the legislature and proportional representation. In standard two-candidate models, voters are simply assumed to vote for their more preferred candidate. That is, voters are sincere. In game-theoretic terms, the refinement of elimination of weakly dominated strategies solves the multiple equilibria problems associated with the "all or none" feature of a two-candidate election.

In our setup, (5) implies that voters in $\left[0, \theta_{D}\right]$ have $D D$ as a weakly dominant strategy and those in $\left[\theta_{R}, 1\right]$ have $R R$. In contrast, those in $\left(\theta_{D}, \theta_{R}\right)$ do not have weakly dominant strategies because the simultaneity of the presidential and legislative votes means that a "best response" for a voter in one contest depends on the outcome of the other. For example, in the presidential election, the legislative vote influences the choice between $D$ and $R$ since $x^{D}$ and $x^{R}$ are functions of the legislative vote. There is only weak dominance in the presidential component in a conditional sense. All voters have weakly dominant strategies, conditional on the legislative vote. Moreover, in the legislative elections, proportional representation causes even conditional weak dominance to vanish. Since $V_{R}$ is continuous, one's "best response" in the legislative component will depend on both the legislative and presidential components used by other voters.

The second problem arises because there is a continuum of voters. If an individual voter's strategy has no measurable impact on policy, then every strategy is Nash for this voter. Analysis of coalitions of voters is a constructive way to overcome not only this problem but, more importantly, the first problem of the absence of dominant strategies.

The "credibility" of coalitions is the third problem we encounter. This problem is highlighted as we turn to a discussion of the properties we believe should be satisfied by a refinement.

Given the incentive voters with ideal points in $\left(\theta_{D}, \theta_{R}\right)$ have to "moderate" outcomes, it is intuitive that there can be only two possible equilibrium outcomes. In one, $D$ wins the presidency and $R$ is relatively strong in the legislature while in the other an $R$ president is balanced by $D$ strength in the legislature. Consider the latter case. It is an almost immediate result that in equilibrium there will be a cutpoint, $\tilde{\theta}_{R}$ such that voters with ideal points left of $\tilde{\theta}_{R}$ vote $D$ for the legislature while those to the right vote $R$. Such a cutpoint is shown in Figure 1 . Moreover, $\tilde{\theta}_{R}=x^{R}$ is the policy outcome if $R$ is president. Thus, as demonstrated by Propositions 1 and 2 below, policy must equal the ideal point of the pivotal voter.

Would a coalition of voters "defect" to another outcome? Voters on the left of $\theta_{D}$, for instance, would want centrist voters now voting $R$ for president to switch their presidential vote in order to elect $D$ president. To attract these 


\section{A Non-credible Coalition}

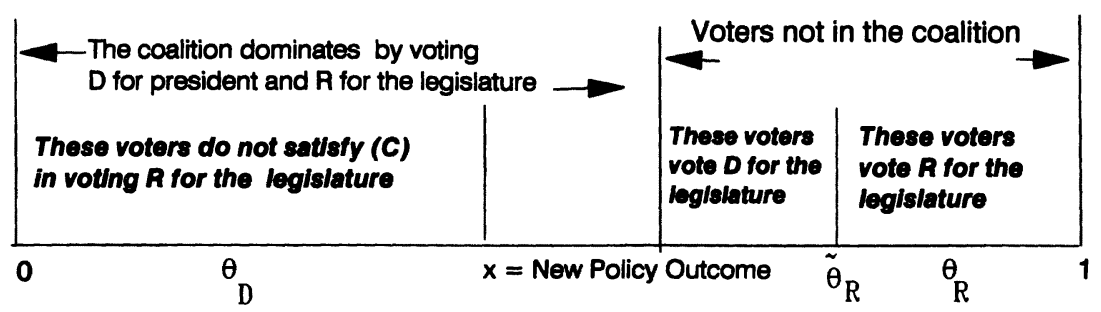

A Credible Coalition

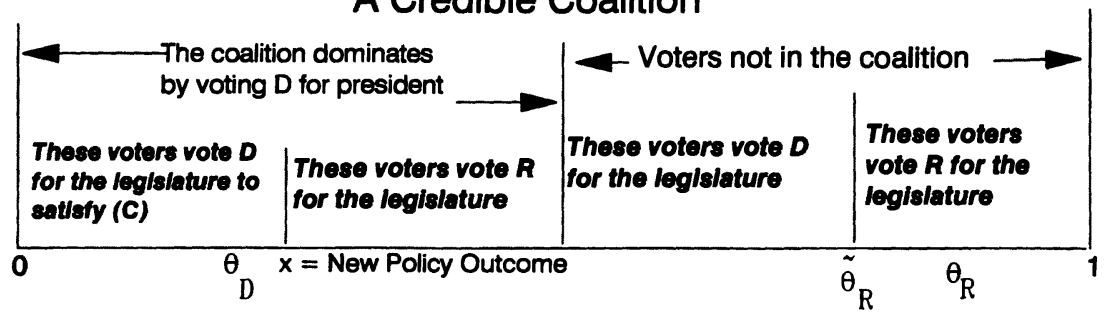

FIGURE 1.-Credible and noncredible coalitions. Both coalitions dominate $\tilde{\theta}_{R}$, the only possible equilibrium outcome with $R$ president. Condition (C) is given in Proposition 1.

voters, the extremists on the left of $\theta_{D}$ would "promise" to vote $R$ for the legislature to "moderate" the $D$ president. This construction is described in the upper panel of Figure 1. However, the vote switches (deviations) proposed to this coalition are not credible: the extremists on the left of $\theta_{D}$ would want to elect $D$ president and vote $D$ for the legislature. ${ }^{11}$ Thus, in order to dominate $\tilde{\theta}_{R}$ credibly, one must find a coalition of voters that has no incentive to vote differently after "defecting." Such a coalition is illustrated in the bottom panel of Figure 1. For at least one of the two possible presidential outcomes, Proposition 4 demonstrates that majority coalitions of the bottom type fail to exist, implying existence of a Nash equilibrium not subject to credible deviations by coalitions.

The coalition proof Nash (CPN) equilibrium concept of Bernheim, Peleg, and Whinston (1987) addresses the problem of credible deviations. CPN in essence restricts which vote-switching deviations are permitted. The basic idea in CPN is that, to be an equilibrium, a strategy constellation $z$ must not only be Nash but not subject to challenge from a credible coalition that internally deviates to some $z^{\prime}$.

Bernheim et al. developed CPN only for the case of a finite number of players. In this case, the concept can be specified recursively. In a single player game, the singleton must be individually rational. For $N$ player games, $N>1$, assume CPN has been defined for games with fewer than $N$ players. For the $N$

\footnotetext{
${ }^{11}$ It will become clear below that this credibility problem applies not only to $\theta_{i} \leq \theta_{D}$, who have a weakly dominant strategy, but also to some $\theta_{i}>\theta_{D}$.
} 
player game, $z$ is (a) self-enforcing if, for all coalitions with $n$ players, $1 \leq n<N$, it is a CPN in the game induced on $n$ by holding the strategies of nonmembers to the strategies used in $z$ and (b) CPN if it is both self-enforcing and strictly Pareto undominated by any other self-enforcing strategy.

This definition implies, in somewhat loose terms, that a "proposal" by a two person coalition is "stable" if it is not subject to an individually rational deviation by its members, that a three person coalition must have a proposal that is not subject to either a credible deviation by any two-person coalition or to an individual deviation, etc.

In the context of our previous example, the CPN refinement says that it is not self-enforcing for extreme-left voters to "promise" to vote $R$ in the legislative election to create a coalition with moderate-left voters who would like to elect a $D$ president but only with strong $R$ representation in the legislature. CPN rules out such coalitions which are not credible in the sense of not being selfenforcing.

In order to apply the same idea to a continuum of voters, we use Greenberg's (1989; 1990, Ch. 7) generalization of the "no credible deviation" approach of CPN. We first restate his stability concept, without specific reference to our game.

Let $z_{i}$ be an individual strategy, $Z^{i}$ be $i$ 's (nonempty and compact) strategy set, $Z^{A}$ the Cartesian product of the $Z^{i}$, and $z$ an element of $Z^{A}$, where $A$ denotes the set of players. Denote by $u_{i}(z) i$ 's utility under $z$, by $S$ and $S^{\prime}$ non-null ${ }^{12}$ subsets of $A$. Allow " $<$ " to express dominance.

Consider the abstract system $(\mathscr{W},<)$ :

$$
\mathscr{W} \equiv\{(S, z) \mid S \subset A, S \neq \varnothing\} .
$$

For $\left(S^{\prime}, z^{\prime}\right)$ and $(S, z)$ in $\mathscr{W}$,

$$
\begin{aligned}
&\left(S^{\prime}, z^{\prime}\right)<(S, z) \Leftrightarrow S \subset S^{\prime}, \quad u_{i}(z)>u_{i}\left(z^{\prime}\right) \\
& \text { for all } i \in S \text { and } z_{l}^{\prime}=z_{l} \text { for all } l \notin S .
\end{aligned}
$$

The abstract core of the system is the set of undominated elements $\mathscr{B}$,

$$
\mathscr{B}=\mathscr{W} \backslash \Delta(\mathscr{W}),
$$

where $\Delta(a)=\{b \in \mathscr{W} \mid b<a)$ and for some subset $\mathscr{K} \subset \mathscr{W}, \Delta(\mathscr{K})=U\{\Delta(a) \mid a$ $\in \mathscr{K}\}$.

Moreover, a set $\mathscr{K}$ is a von Neumann-Morgenstern abstract stable set if $\mathscr{K}=$ $\mathscr{W} \backslash \Delta(\mathscr{K})$. That is, $\mathscr{K}$ is internally stable (for all $(S, z)$ and $(T, y) \in \mathscr{K}$, neither $(S, z)<(T, y)$ nor $(T, y)<(S, z))$ and externally stable (for every $(S, z) \notin \mathscr{K}$, $\exists(T, y) \in \mathscr{K}$ such that $(S, z)<(T, y))$.

\footnotetext{
${ }^{12}$ We need only consider non-null subsets since no null subset can affect outcomes and thus individual utilities.
} 
THEOREM (Greenberg (1989)): For a finite set of players $N$, if an abstract stable set $\mathscr{K}$ exists, $(N, z) \in \mathscr{K}$ if and only if $z$ is in the set of $C P N$ for the normal form of the game defined for $N$.

In other words, Greenberg shows a correspondence between abstract stable sets and CPN for a finite number of players. Consequently, we use the abstract stable set, which is also defined for the continuum, as a generalization of the CPN concept. For our model, the abstract stable set has a simple characterization; it is the unique set of pairs that are undominated by members of the abstract core. With a slight abuse of terminology we will indicate the pair(s) $(I, z)$ in this stable set as CPN equilibria for this game.

\section{EQUILIBRIUM}

\subsection{Legislative Elections: A Condition on Dominance}

Let us define $V_{R}^{i J_{z}}$ as the legislative vote bliss point for voter $i$ given the presidential outcome under $z$.

From the single-peakedness of $u(\cdot)$, the following result follows immediately:

LEMMA 1: For fixed $J_{z}, u(\cdot)$ is continuous and single-peaked in $V_{R}$. Bliss points $V_{R}^{i J_{z}}$ are monotonically increasing in $\theta$.

We now state an important result concerning voting in legislative elections.

Proposition 1: A necessary and sufficient condition for $(S, z)$ to be undominated by any $(T, y)$ where $y^{1}=z^{1}$ is

(C) $\quad z^{2}$ be represented on $S$ by a cutpoint $\tilde{\theta}$ satisfying

$$
V_{R z}\left\{\begin{array}{l}
> \\
= \\
<
\end{array}\right\} V_{R}^{i J_{z}} \text { if } \quad \theta_{i}\left\{\begin{array}{c}
< \\
= \\
>
\end{array}\right\} \tilde{\theta} .
$$

Proof: If (C) is not satisfied, either (a) $T=\left\{i: i \in S\right.$ and $z_{i}^{2}=D$ and $V_{R z}<$ $\left.V_{R}^{i J_{z}}\right\} \neq \varnothing$ or (b) $L=\left\{i: i \in S\right.$ and $z_{i}^{2}=R$ and $\left.V_{R z}>V_{R}^{i J_{z}}\right\} \neq \varnothing$. Without loss of generality, assume $T \neq \varnothing$. By continuity and by the single-peakedness of $u(\cdot)$ given $J_{z}$, there exists a coalition $T^{\prime} \subset^{\prime} T$ all of whose members utility would be increased were $y_{i}^{2}=R, i \in T^{\prime}$, and $y_{i}^{2}=z_{i}^{2}, i \notin T^{\prime}$. So an $(S, z)$ that does not satisfy $(\mathrm{C})$ is dominated.

The proof of sufficiency is immediate.

Q.E.D.

COROLLARY: Any pair $(S, z)$, where $z$ is not a legislative cutpoint strategy on $S$, is dominated by some $(T, y)$, where y satisfies $(C)$ on $T$. 
Proposition 1 has the appealing property that there are no voters who would like to see a reduction of the share of votes of the party they are voting for in the legislative election.

We now establish a result that resembles the median voter theorem. In traditional two party electoral models, policy equals the bliss point of the median voter. In our model, policy equals the bliss point of the pivotal voter in the legislative election; this is the pivotal voter theorem. Before considering the full game, where voters simultaneously choose the executive and the legislature, we present this theorem in the context of a restricted game where the president is exogenously given and voters choose only the legislature.

From the continuity and strict monotonicity of the functions $H(\cdot)$ and $g(\cdot)$ on $[0,1]$, there are unique solutions for $\theta$ and $V_{R}$ to the following pairs of equations:

$$
\begin{aligned}
& \left\{\begin{array}{l}
V_{R}=1-H(\theta), \\
\theta=x^{D}=\theta_{D}+g_{D}\left(V_{R}\right),
\end{array}\right. \\
& \left\{\begin{array}{l}
V_{R}=1-H(\theta), \\
\theta=x^{R}=\theta_{R}-g_{R}\left(1-V_{R}\right) .
\end{array}\right.
\end{aligned}
$$

Define $\tilde{\theta}_{D}, \tilde{\theta}_{R}$, respectively, as the solutions for $\theta$ to (6) and (7).

Proposition 2-Pivotal Voter Theorem: The cutpoint strategy $\tilde{\theta}_{j}, j \in\{D, R\}$, represents the unique $(I, z) C P N$ pair in the restricted game where $j$ is president. The following holds:

$$
\theta_{D}<\tilde{\theta}_{D}=x^{D}<\tilde{\theta}_{R}=x^{R}<\theta_{R} .
$$

Proof: 1 . It is direct to show that $\tilde{\theta}_{j}$ satisfies $(C)$ for $\left(I, \tilde{\theta}_{j}\right)$ and that any $(I, z)$ that involves measurable deviations from $\tilde{\theta}_{j}$ fails to satisfy (C).

2. By Proposition 1 , there is a unique abstract stable set $\mathscr{K}^{*}=\mathscr{B}=\{(S, z)$ such that $(C)$ is satisfied\}.

3. Steps 1 and 2 imply that $\left(I, \tilde{\theta}_{j}\right)$ is the unique $(I, z)$ CPN pair.

4. The inequalities (8) follow immediately by noting that if (C) is satisfied for $\tilde{\theta}_{R}$ and if $\tilde{\theta}_{D} \geq \tilde{\theta}_{R},(5)$ implies that (C) cannot be satisfied for $\tilde{\theta}_{D}$ Q.E.D.

Proposition 2 holds regardless of the positions of $\theta_{D}$ and $\theta_{R}$ relative to the median voter; the pivotal voter is always interior to the bliss points of the two parties, even if they are both to the same side of the median.

Conditions (8) establish that the policy outcome equals the ideal point of the voter at the legislative cutpoint. ${ }^{13}$ Every voter to the left of the cutpoint votes $D$

\footnotetext{
${ }^{13}$ It should now be clear why we assumed a continuum of voters. A discrete distribution would introduce tedious but substantively uninteresting problems emerging from the fact that changing one vote makes a discrete change in policy. For example, assume there were 100 voters each with a distinct ideal point and that the most desirable outcome for voters 68 and 69 from the left would be for party $D$ to obtain 68 legislative votes and that voter 70 from the left preferred to see $D$ obtain 67 votes. Then there would be two equilibria. One where voters 1-68 voted $D$ and 69-100 voted $R$ and another which was the same except voter 68 voted $R$ and 69 voted $D$.
} 
and would want a policy further to the left, thus a reduction in $V_{R}$. A similar statement applies to voters to the right of the cutpoint. The cutpoint equilibrium results in voters pulling policy away from the incumbent president's bliss point; voters moderate the president with the legislature. Since $\tilde{\theta}_{D}<\tilde{\theta}_{R}$ a party receives more votes for the legislative elections when it does not win the presidency than when it does.

\subsection{Simultaneous Choice of Executive and Legislature}

We now analyze the unrestricted game in which voters jointly choose the executive and the legislature. We begin with three definitions. Then we characterize the abstract core. Finally, we show that the abstract stable set (CPN) is the set of pairs that are undominated by members of the abstract core.

DEFINITION: $S$ is pivotal under $z$ if

$$
\begin{aligned}
\sigma(S)+\sigma\left\{i: i \in I \backslash S \text { and } z_{i}^{1} \neq J_{z}\right\} & \geq \frac{1}{2} \quad \text { if } \quad J_{z}=D, \\
& >\frac{1}{2} \quad \text { if } \quad J_{z}=R .
\end{aligned}
$$

That is, pivotal coalitions can change the outcome of the presidential election when the votes of nonmembers are unchanged. (Recall that we assume ties go to party $R$.)

DEFINITION: $\theta_{\bar{T}}$ is the supremum of the ideal points of the members of $T$.

DefinITION: $x_{z}^{j}$ is the policy when $j$ is president with legislative vote $V_{R z}$.

The next result shows that, if $(C)$ is satisfied on $(S, z)$ when $R$ is president, the pair can only be dominated by a coalition of left voters, more precisely voters with bliss points to the left of the policy outcome under $z$.

Lemma 2-Dominating Pivotal Coalitions: If $J_{z}=R$ and $(S, z)<(T, y),(C)$ satisfied for $(S, z)$ implies $\theta_{i}<x_{z}^{R}$ for all $i \in T$.

Proof: 1. Domination and (C) satisfied imply $J_{y}=D$.

2. Assume the contrary. Then $\exists i \in T \cap\left(x_{z}^{R}, 1\right]$ with $u\left(x_{y}^{D}, \cdot\right)>u\left(x_{z}^{R}, \cdot\right)$. Therefore, by single-peakedness $x_{y}^{D}>x_{z}^{R}$ and $T \subset\left(x_{z}^{R}, 1\right]$.

3. Inequality (5) and $x_{y}^{D}>x_{z}^{R}$ imply $V_{R y}>V_{R z}$ while (C) satisfied on $S$ implies $z_{i}^{2}=R$ for all $i \in T$. Contradiction.

Q.E.D.

Given that a "left" coalition must pivot against $R$ president, the next lemma gives the necessary and sufficient conditions for the rightmost member of that coalition to gain utility in deviating. In turn, if the rightmost member gains, all members gain. 
LEMMA 3: If $J_{z}=R$ and $(C)$ is satisfied on $(S, z),(S, z)$ is dominated if and only if $\exists(T, y), T \subset S$ such that

(i) $J_{y}=D$,

(ii) $u\left(x_{y}^{D}, \theta_{\bar{T}}\right) \geq u\left(x_{z}^{R}, \theta_{\bar{T}}\right)$,

(iii) $y_{i}=z_{i}, i \notin T$.

Proof: Sufficiency. By Lemma 1 and Lemma 2, to show that all members of $T$ are better off, it suffices to focus on voter type $\theta_{\bar{T}}$. If (ii) is satisfied and (iii) is satisfied and $T \subset S$, the conditions for dominance are satisfied.

Necessity. Proposition 1 and (C) satisfied imply that (i) is necessary. The definition of dominance implies that (iii) is necessary. Since all members of $T$ must be better off under $y$ than under $z$, (ii) is necessary.

Q.E.D.

Proposition 3-The Abstract Core: A pair $(S, z) \in \mathscr{B}$ if $(C)$ is satisfied and (a) $S$ is nonpivotal or (b) $S$ is pivotal for $z$, and there does not exist $(T, y)$ that satisfies the conditions of Lemma 3 if $R$ is president under $z$ or analogous conditions if $D$ is president under $z$.

PRoof: Follows directly from Proposition 1 and Lemma 3.

PROPOSITION 4-CPN Equilibria: There is a unique abstract stable set $\mathscr{K}^{*}=$ $\mathscr{W} \triangle(\mathscr{B})$ that contains at least one $C P N$ pair $(I, z)$. If $(I, z) \in \mathscr{H}^{*}$, either party $R$ wins the presidency and $\tilde{\theta}_{R}$ is the cutpoint of the legislative elections or party $D$ wins the presidency and $\tilde{\theta}_{D}$ is the legislative cutpoint.

Proof: External Stability-External stability is direct since $\mathscr{B} \subset \mathscr{W} \backslash \Delta(\mathscr{B})$.

Internal Stability - If $(S, z) \in \mathscr{B}$, it is undominated.

Therefore consider $(S, z) \in \mathscr{K}^{*}$ but $(S, z) \notin \mathscr{B}$. Assume $(S, z)<(T, y)$ and $(T, y) \in \mathscr{K}^{*}$. Since (C) is satisfied on $S, J_{y} \neq J_{z}$. If $(T, y) \in \mathscr{K}^{*},(T, y)$ satisfies (C). Moreover, the fact that members of $T$ prefer the $y$ outcome to the $z$ outcome immediately implies that no $T^{\prime} \subset T$ can gain by pivoting back to $J_{z}$. Hence $(T, y) \in \mathscr{B}$. But then $(S, z)<(T, y) \Rightarrow(S, z) \notin \mathscr{K}^{*}$. Contradiction.

Consequently, all $(S, z) \in \mathscr{W} \backslash \Delta(\mathscr{B})$ are internally stable.

Uniqueness-For every abstract stable set $\mathscr{K}, \mathscr{B} \subset \mathscr{K}$. By internal stability, therefore, $\mathscr{K} \cap \Delta(\mathscr{B})=\varnothing$. Therefore, every $\mathscr{K} \subset \mathscr{K}^{*}$. But, by the internal stability of $\mathscr{K}^{*}$, any $\mathscr{K} \neq \mathscr{K}^{*}$ is not externally stable. Hence, $\mathscr{K}^{*}$ is the unique abstract stable set.

$(I, z)$ in the $C P N$-Assume w.l.o.g. that $u\left(\tilde{\theta}_{R}, \mu\right) \geq u\left(\tilde{\theta}_{D}, \mu\right)$ and let $z$ be a cutpoint strategy represented by $\hat{\theta}<\mu, \tilde{\theta}_{R}$. Claim: $(I, z) \in \mathscr{R}^{*}$. Assume the contrary, implying $(I, z)<(T, y) \in \mathscr{B}$ with $J_{y}=D$ and $x_{y}^{D} \leq \tilde{\theta}_{D}$. But by singlepeakedness $u\left(x_{y}^{D}, \mu\right) \leq u\left(\tilde{\theta}_{D}, \mu\right)$ and by assumption $u\left(\tilde{\theta}_{D}, \mu\right) \leq u\left(\tilde{\theta}_{R}, \mu\right)$. Hence $\mu \notin T$ which contradicts $J_{y}=D$. Thus, $x_{z}^{R}=\tilde{\theta}_{R}$ is a CPN outcome. Q.E.D.

Remarks: 1. Ties Are Never Equilibria. Our assumption about the tie-breaking rule is inconsequential. If $0<P<1$ when $M_{R z}=\frac{1}{2}$, any pair $(I, z)$ that 
implies a tied presidential election is not CPN. (See Alesina and Rosenthal (1993).) The intuition is that the voters can more effectively moderate the executive in the absence of uncertainty about the election. The only CPN outcomes have a sure winner. This result holds even with complete symmetry. In contrast to the traditional two-candidate model, where complete convergence always implies a tie, ties are never equilibria in our model.

Consider the fully symmetric case provided by $P=\frac{1}{2}$, symmetric $u(\cdot), g(\cdot)$, and $H(\cdot)$, with $\theta_{D}$ and $\theta_{R}$ symmetric about $\mu$. This is the most likely candidate for a tied race. With full symmetry, a tie implies $\tilde{\theta}=\mu$. Therefore the policy outcomes are more extreme than $\tilde{\theta}_{R}$ and $\tilde{\theta}_{D}$; if $D$ wins the coin toss $x^{D}<\tilde{\theta}_{D}$ and if $R$ wins $x^{R}>\tilde{\theta}_{R}$. A coalition of voters around the median can "dominate" the tie by making certain, say, $R$ is president and reinforcing the $D$ delegation in the legislature to obtain a more moderate outcome than $x^{D}$. Some voters below $\mu$ switch to an $R$ presidential vote and some voters above $\mu$ switch to a $D$ vote for the legislature. (Note that this deviation from a tie leads to divided government; party $R$ has the presidency and $D$ has a majority in the legislature.)

2. Conditions for Two us. One CPN Outcomes. Proposition 4 implies that there are either one or two CPN outcomes. For symmetric $g(\cdot), H(\cdot)$, and $u(\cdot)$, if the two party ideal positions $\left(\theta_{D}\right.$ and $\left.\theta_{R}\right)$ are relatively symmetric around the median, we have two equilibria (i.e., a $D$ executive with a relatively strong $R$ legislative delegation and vice versa). If, instead, $D$, for example, is much closer to the median than $R$, there is a unique equilibrium with $D$ president. In particular, there is a unique CPN when both party ideal points are to the same side of the median.

3. Divided Government. There exist equilibria for which divided government occurs; that is, the party winning the presidency does not have a majority in the legislature. When there are two CPNs, at least one must have divided government. ${ }^{14}$ Divided government also can arise when the CPN is unique.

4. Conditional Sincerity. In a CPN equilibrium at least a bare majority of the presidential winner's support must come from voters who, given the legislative component of the strategy, prefer the winner. This result follows from the structure of the proof of Propositions 3 and 4. Similarly, condition (C) implies that, conditional on the presidential vote, all voters must vote sincerely in the legislative election.

\subsection{An Example}

We now present an example which leads to closed form solutions and several additional results. The same specification forms the basis of the uncertainty model in Section 5. 2.

\footnotetext{
${ }^{14}$ PROOF: For both CPN to have unified government, $\tilde{\theta}_{D}>\mu>\tilde{\theta}_{R}$, which contradicts Proposition
} 
This example assumes symmetric preferences that are uniformly distributed on [0,1]. We also assume linear $g_{j}(\cdot) ; g_{D}=k V_{R}, g_{R}=k\left(1-V_{R}\right)$. This leads to:

$$
\begin{aligned}
& x^{D}=\theta_{D}+k V_{R}, \\
& x^{R}=\theta_{R}-k\left(1-V_{R}\right) .
\end{aligned}
$$

Note that $\left(2^{\prime}\right)$ and $\left(3^{\prime}\right)$ represent policy as a weighted average of the bliss points of the executive and the legislature with the weight $\alpha \in(0,1)$ implicitly given by:

$$
k \equiv(1-\alpha)\left(\theta_{R}-\theta_{D}\right) .
$$

That is,

$$
\begin{aligned}
& x^{D}=\alpha \theta_{D}+(1-\alpha)\left[V_{R} \theta_{R}+\left(1-V_{R}\right) \theta_{D}\right], \\
& x^{R}=\alpha \theta_{R}+(1-\alpha)\left[V_{R} \theta_{R}+\left(1-V_{R}\right) \theta_{D}\right] .
\end{aligned}
$$

The position of the legislature is also a weighted average, the weights being the vote shares of the two parties. Using $\left(2^{\prime}\right),\left(3^{\prime}\right)$, and $H$ uniform, we obtain

$$
\begin{aligned}
& \tilde{\theta}_{D}=\frac{\theta_{D}+k}{1+k}, \\
& \tilde{\theta}_{R}=\frac{\theta_{R}}{1+k} .
\end{aligned}
$$

1. The Relative Power of the Presidency and the Legislature. If the executive is more powerful than the legislature, i.e. $\alpha>\frac{1}{2}$, divided government occurs unless the parties are very asymmetrically located with respect to the median. As $\alpha \rightarrow 1$, power becomes concentrated in the presidency and only one CPN survives for $\theta_{D} \neq 1-\theta_{R}$. The case of $\alpha=1$ is the standard two-party model where the winner is the party closer to the median. In our model, if $\alpha \cong 1$, this party wins the presidency. In the face of an all powerful president, if the party bliss points are on opposite sides of the median voter's, the legislature is handed to the opposition; the government is always divided. As $\alpha \rightarrow 0$, power becomes concentrated in the legislature. Here also there is a unique CPN but with unified government. As $\alpha \rightarrow 0$, if, say, $R$ is closer to the median, $\tilde{\theta}_{R} \rightarrow \theta_{R} /(1+$ $\left.\theta_{R}-\theta_{D}\right)<\frac{1}{2}=\mu$. With $R$ president, voters on the left use the power of the legislature to pull policy to the left of the median.

The basic nature of these observations carries over to the more general $g_{J}(\cdot)$ functions. In particular, with a powerful president, strong legislative opposition is needed for balancing; thus, divided government becomes more likely. The two possible equilibrium outcomes, $\tilde{\theta}_{R}$ and $\tilde{\theta}_{D}$, depend only on the $g_{J}(\cdot)$ and $H(\cdot)$. Whether both or just one of these outcomes is CPN also depends on the "shape" of $u(\cdot)$.

2. One vs. Two CPN Outcomes. In our example, it is easy to find the parameter values which lead to one or two CPN outcomes, with or without 
divided government. For instance, with $\alpha=\frac{1}{2}$, we have:

(i) $\theta_{R}=.9, \theta_{D}=.1 \Rightarrow$ two CPN equilibria, $\tilde{\theta}_{R}=.36, \tilde{\theta}_{D}=.64$, divided government in both.

(ii) $\theta_{R}=.9, \theta_{D}=.3 \Rightarrow$ unique $\mathrm{CPN}$ with $D$ president, $\tilde{\theta}_{D}=.46$, divided government.

(iii) $\theta_{R}=.9, \theta_{D}=.4 \Rightarrow$ unique CPN with $D$ president, $\tilde{\theta}_{D}=.52$, unified government.

Case (iii) illustrates that, in the example of this section, there is a unique CPN with unified government if both $\tilde{\theta}_{D}$ and $\tilde{\theta}_{R}$ are to the same side of the median, even if the bliss points are on opposite sides of the median. This result implies immediately that, if there are two CPN outcomes, both have divided government, as illustrated by case (i). Case (ii) illustrates that divided government can also occur when there is a unique CPN.

3. Heterogeneous Parties. We can relax the assumption of intra-party homogeneity by allowing the executive $(E)$ and the legislative $(L)$ delegation of the same party to have different ideal policies. For simplicity, we continue to assume homogeneity within legislative delegations. The ideal policies are denoted $\theta_{j h}$ where $j \in\{D, R\}$ and $h \in\{E, L\}$. Thus, the first subscript identifies the party, the second identifies the "executive" or the "legislative" branch of the party. We assume only the following:

$$
\theta_{D h}<\theta_{R h^{\prime}} \quad\left(h=E, L ; h^{\prime}=E, L\right) .
$$

Thus, in both parties the executive may or may not be more moderate than the legislative delegation. If party $j$ holds the executive, policy is given by the following generalization of $\left(2^{\prime \prime}\right)$ and $\left(3^{\prime \prime}\right)$ :

$$
x^{j}=\alpha \theta_{j E}+(1-\alpha)\left[V_{R} \theta_{R L}+\left(1-V_{R}\right) \theta_{D L}\right] .
$$

It can be shown that three basic results obtained in the homogeneous case apply here as well: (i) in the case of $u(\cdot)$ symmetric, whichever $\tilde{\theta}_{j}$ is closer to the median is a CPN equilibrium; (ii) the legislative vote for a party is always higher when the party does not control the executive; (iii) for some parameter values "divided government" is possible.

In the homogeneous case, policy outcomes were always in between the ideal policies of the two presidents. When does this result continue to hold; that is, are presidents moderated by the legislature? To address this question we focus, without loss of generality, on the case of $D$ president, the case of $R$ president being symmetric. In the more interesting case in which the two parties are on opposite sides of the median, simple algebraic manipulation then shows that, for $u(\cdot)$ symmetric, the president is moderated if any of the following three conditions holds:

(i) $\theta_{D E} \leq \frac{1}{3}$. Executives are always moderated if they are further than $\frac{1}{6}$ from the median.

(ii) $\theta_{D L}+\theta_{R L}=1$. Executives are always moderated if the legislative parties are symmetric about the median. 
(iii) $\theta_{D L} \geq \theta_{D E}$. An executive who is more extreme than his legislative party is always moderated.

When none of these conditions hold, the policy outcome may be more extreme than the president's ideal point. In this case a "moderate" president balances an extreme legislature.

\section{THE TWO PERIOD MODEL}

In the two-period model, the setup is identical to the one-period model except that preferences are intertemporally additive with discount factor $\beta$. In the first period, legislative and presidential elections are held simultaneously; in the second, the executive remains in office and new legislative elections are held. This scenario is intended to capture the structure of elections in the United States.

An individual strategy becomes $Z^{i} \equiv z_{i}^{1} z_{i}^{2} z_{i}^{3}$ where the first two components remain as in the one-period model and $z_{i}^{3} \in\{D ; R ; D$ if $R$ president in period 1 , $R$ if $D$ president in period $1 ; R$ if $R$ president in period $1, D$ if $D$ president in period 1$\}.^{15}$

In our characterization of equilibrium behavior in the two-period model, we require that the behavior of voters be dynamically consistent. Bernheim et al. (1987) combined the concepts of dynamic consistency and coalition-proofness in defining perfectly coalition-proof Nash equilibrium. Here we simply extend Greenberg's (1989) dominance concept in a way that is directly analogous to the development of Bernheim et al., ${ }^{16}$ as follows.

Let $\gamma$ be the generic index for subgames (including the game itself), and let $z(\gamma)$ be the restriction of $z$ to the subgame.

For $\left(S^{\prime}, z^{\prime}\right)$ and $(S, z)$ in $\mathscr{W}$,

$$
\left(S^{\prime}, z^{\prime}\right)<(S, z) \Leftrightarrow
$$

$$
S \subset S^{\prime},
$$

$$
z_{l}^{\prime}=z_{l} \text { for all } l \notin S \text {, }
$$

$$
u_{i}(z(\gamma)) \geq u_{i}\left(z^{\prime}(\gamma)\right) \text { for all } i \in S \text { in every subgame } \gamma \text {, with strict }
$$

inequality in at least one subgame.

Conditions (i) and (ii) repeat Greenberg's definition of dominance. Condition (iii) adds dynamic consistency to Greenberg's specification. For dominance to occur, there must be at least one subgame in which all members of $S$ are better off with $z$ than with $z^{\prime}$. In addition, there can be no subgame in which any member of $S$ is worse off. In our game, there are two subgames, one corre-

\footnotetext{
${ }^{15}$ It is unnecessary to condition $z^{3}$ on the $t=1$ vote shares, since the presidential share does not affect utilities and the legislature is entirely reelected in period 2 .

${ }^{16}$ In this paper, we do not attempt to prove that the abstract stable set for our dominance relation is, parallel to Greenberg (1989), isomorphic with the perfectly coalition-proof Nash equilibria.
} 
sponding to the second period with a $D$ president, the other to $R$ president. Proposition 2, the pivotal voter theorem, gives the unique CPN outcome in each subgame. Note that even if $z$ implies $R$ president, $z$ will be dominated if it does not satisfy a $C$ condition in the second period for $D$ president.

With no uncertainty about preferences, in equilibrium the outcome of the presidential election is known before the first-period elections. Since no information is revealed by the first-period elections, voter behavior does not change in the second period. This implies that the equilibrium cutpoints in the legislative elections in the two periods are identical.

\section{Proposition 5: In equilibrium the legislative vote is identical in both periods.}

More precisely, in the Appendix we show that the results of Proposition 4 extend to the two-period case. The two-period stable set $(I, z)$ pair(s) are identical to those of Proposition 4 with the addition that the first-period legislative component $\tilde{\theta}_{R}$ or $\tilde{\theta}_{D}$ is repeated in the second period. The proof requires two technical restrictions. One is that policies with a $D$ president are always to the left of policies with a $R$ president. The other is that preferences follow a single-crossing property.

Proposition 5 implies that there is no midterm cycle with complete information.

\section{THE MODEL WITH UNCERTAINTY: THE MIDTERM CYCLE}

\subsection{The Model with Incomplete Information}

This section considers the case in which the distribution of voters' preferences is perturbed by a random shock. The presence of this form of uncertainty will cause some voters to alter their legislative votes over the two periods, leading to a midterm cycle.

We assume intertemporally additive, quadratic preferences for both parties and voters:

$$
u_{i}=-\frac{1}{2} \sum_{t=1}^{2} \beta^{t-1}\left(x_{t}-\theta_{i}\right)^{2}, \quad i=D, R, i .
$$

We also assume $H(\theta)$ uniform and the linear policy functions given in $\left(2^{\prime}\right)$ and $\left(3^{\prime}\right)$. Quadratic preferences imply the single-crossing property assumed in the two-period complete information model. Also as with the two-period complete information case, we assume that policies with $D$ president are always to the left of those with an $R$ president; this is equivalent to assuming $\alpha \geq \frac{1}{2}$.

The extremes of the uniform distribution of voters ideal points are given by $I_{t}=\left[a_{t}, 1+a_{t}\right]$ where the $a_{t}$ are i.i.d. for all $t$ as

$$
a_{t} \sim U[-w,+w], \quad w<\theta_{D}<\theta_{R}<1-w .
$$


Thus, for any realization of $a$ (henceforth the time subscript is omitted when unnecessary) there is always a constant proportion $\left(\theta_{R}-\theta_{D}\right)$ of the electorate with ideal points in the interval $\left[\theta_{D}, \theta_{R}\right]$. The distribution of $a$ is "common knowledge," but voters cannot communicate their preferences to each other. ${ }^{17}$ Moreover, even though the realization of $a_{1}$ is automatically revealed by the observed results of the $t=1$ elections, the assumption of independence implies that we have no learning in the game.

Greenberg (1989) does not define $\mathscr{K}$ for a game of incomplete information, but we make a natural generalization. We define coalitions with respect to voter types that can lie in the interval $I_{w}=[-w, 1+w]$. Domination $(<)$ is defined relative to the expected utility of each type in the coalition.

Note that, generically, the set of voters differs in the two time periods. For example, if $a_{2}>a_{1}$, there are voters in the interval $\left[a_{1}, a_{2}\right)$ in the first period but not in the second and voters in the interval $\left(1+a_{1}, 1+a_{2}\right]$ in the second period but not the first. Since all period 1 voters who risk not participating in period 2 have weakly dominant strategies, the analysis below is unaffected by having some players participate for only one period. ${ }^{18}$

\subsection{Voting in Legislative Elections}

We begin by considering the legislative elections at $t=2$. The analysis parallels Section 3.1. The vote for the legislature, which now depends on the realization of $a$, is denoted $V_{R}(a)$. The expected second-period utility of voter $i$, with a bliss point $\theta_{i}$ such that $\theta_{R} \leq \theta_{i} \leq \theta_{D}$ when $R$ is president is given by

$$
E u_{i}^{R}=\int_{-w}^{w}-\frac{1}{2}\left(\theta_{R}-k\left(1-V_{R}(a)\right)-\theta_{i}\right)^{2} \frac{1}{2 w} d a .
$$

An analogous expression for $E u_{i}^{D}$ holds if $D$ is president. Voters with bliss points $\theta_{i}<w$ or $\theta_{i}>1-w$, can update by observing their own preferences. But the inequalities in (14) imply that these voters have dominant strategies for every realization of $a$ : they always vote $R R$ or $D D$ respectively. Thus, their updating does not affect the equilibrium analysis.

${ }^{17}$ One might be concerned that, if coalitions can be formed, communication must be possible. We argue, however, that communication is unimportant in our model. The only preferences that are unknown are those of voters with weakly dominant strategies. These voters always have an interest in not revealing their existence since they always have an interest in having the other voters behave as if there were very few of them. Thus any cheaptalk will be babble. Communication is but a small part of the more general issue of how coalitions are formed in very large electorates. We only view CPN as an "as if" description of tacit processes in elections.

${ }^{18}$ The varying players interpretation of the models can be motivated by the assumption that electoral participation is predominantly driven by nonvoting from alienation (Hinich and Ordeshook (1969); Rosenthal and Sen (1973)) where nonvoters are disproportionately extremists. But it would fail to take into account nonvoting by indifferent middle-of-the-road voters. The set of voters would not change if we permitted a shock to occur only in the first period. The first-period vote reveals the shock $a$ to the electorate which then plays the second period with complete information. None of our results would change qualitatively with this formalization, but the algebra and the presentation would be somewhat more cumbersome. 
In the Appendix, we show that (14) and the assumption of quadratic preferences allow us to express the relevant indirect preferences in terms of expected votes. Let $E V_{R z}^{2 j}$ denote the expected vote at $t=2$ when $j$ has won the presidency at $t=1$. Let $E V_{R}^{2 i j}$ denote voter $i$ 's indirect bliss point; $\tilde{\theta}_{j 2}$ is a legislative cutpoint in period 2 when party $j$ holds the presidency.

Proposition 6 (Pivotal Voter Theorem for Incomplete Information): A necessary and sufficient condition for $(S, z)$ to be undominated by any $(T, y)$ where $y^{1}=z^{1}$ and $y^{2}=z^{2}$ is that:

$\left(\mathrm{C}^{2}\right) \quad z^{3}$ (second-period component) be represented on $S$ by cutpoints $\tilde{\theta}_{j 2}$ satisfying:

$$
E V_{R z}^{2 j}\left\{\begin{array}{l}
> \\
= \\
<
\end{array}\right\} E V_{R}^{2 i j} \text { if } \quad \theta_{i}\left\{\begin{array}{c}
< \\
= \\
>
\end{array}\right\} \tilde{\theta}_{j 2} .
$$

Moreover:

$$
\begin{aligned}
& \tilde{\theta}_{R 2}^{*}=\tilde{\theta}_{R}=\frac{\theta_{R}}{1+k} \text { is the cutpoint of any CPN at } t=2 \text { for } R \text { president } \\
& \tilde{\theta}_{D 2}^{*}=\tilde{\theta}_{D}=\frac{\theta_{D}+k}{1+k} \text { is the cutpoint of any } C P N \text { at } t=2 \text { for } D \text { president } \\
& x^{R 2}=\frac{\theta_{R}}{1+k}+k a_{2} \text { is the policy with a } R \text { president } ; \\
& x^{D 2}=\frac{\theta_{D}+k}{1+k}+k a_{2} \text { is the policy with a } D \text { president } \\
& \tilde{\theta}_{R 2}^{*}=E\left(x^{R 2}\right) ; \quad \tilde{\theta}_{D 2}^{*}=E\left(x^{D 2}\right)
\end{aligned}
$$

Proof: See Appendix.

The analogy with the complete information case is that the expected policy is equal to the ideal policy of the pivotal voter $\left(\tilde{\theta}_{R 2}^{*}\right.$ or $\left.\tilde{\theta}_{D 2}^{*}\right)$.

Let us now turn to the first-period election. Let $E V_{R z}^{1 i}$ denote $i$ 's expected vote bliss point for the legislative elections at $t=1$ given the presidential component of $z$. (Note that the separability of (13) and the assumption that the entire legislature is elected in both periods imply that the $t=1$ legislative bliss point depends on presidential voting only and not on expectations concerning the second period.) Let $P_{z}$ be the ex ante probability that $R$ is president, that is the probability when all voters believe that $z$ will be the strategy but do not know $a .{ }^{19}$ Note that

$$
P_{\hat{\theta}}=\frac{1}{2 w}\left[\frac{1}{2}+w-\hat{\theta}\right]
$$

${ }^{19}$ Note that if $\hat{\theta}$ is a presidential cutpoint in $z, \operatorname{Prob}\left(M_{R z}=\frac{1}{2}\right)=0$, implying that the tie-breaking rule is inconsequential. 
For the first period, Proposition 6 and the results developed in the certainty model can be directly extended to show the following.

LEMMA 4: A necessary and sufficient condition for $(S, z)$ to be undominated by any $(T, y)$ where $y^{1}=z^{1}$ and $y^{3}=z^{3}$ is that

$\left(\mathrm{C}^{2}\right) \quad z^{2}$ ( first-period legislative component) be represented on $S$

by a cutpoint $\tilde{\boldsymbol{\theta}}$ satisfying:

$$
E V_{R z}^{1}\left\{\begin{array}{c}
> \\
= \\
<
\end{array}\right\} E V_{R}^{1 i} \text { if } \quad \theta_{i}\left(\begin{array}{c}
< \\
= \\
>
\end{array}\right\} \tilde{\theta} .
$$

LEMMA 5: 1. A necessary and sufficient condition for $\left(I_{w}, z\right)$ to be undominated by any $(T, y)$ where $y$ differs from $z$ only in the $t=1$ legislative component is that the $t=1$ legislative component of $z$ be the cutpoint $\tilde{\theta}(z)$, given by

$$
\tilde{\theta}(z)=P_{z} \tilde{\theta}_{R}+\left(1-P_{z}\right) \tilde{\theta}_{D} .
$$

2. If $z$ has a presidential cutpoint $\hat{\theta}$,

$$
\left(\begin{array}{ll}
\tilde{\theta}_{R}, & \hat{\theta} \leq \frac{1}{2}-w \quad\left(P_{\hat{\theta}}=1\right), \\
\left(\frac{1}{2}+w-\hat{\theta}\right)
\end{array}\right.
$$

Proof: See Appendix.

The next result follows immediately from Lemma 5.

Proposition 7: Given $0<P_{z}<1$, a necessary condition for nondomination of $\left(I_{w}, z\right)$ is that $z$ be represented by a unique legislative cutpoint $\tilde{\theta}(z)$ at $t=1$ satisfying

$$
\tilde{\theta}_{D 2}^{*}<\tilde{\theta}(z)<\tilde{\theta}_{R 2}^{*} .
$$

The intuition of this result is straightforward. If, say, $\tilde{\theta}(z)<\tilde{\theta}_{D 2}^{*}$, then voters with bliss points $\theta_{i}$ such that $\tilde{\theta}(z)<\theta_{i}<\tilde{\theta}_{D 2}^{*}$, under uncertainty about the president's identity, vote $R$ for the legislature in the first period. This implies that they would want to "moderate" a $D$ president despite the fact that they are taking the risk of making a $R$ president less constrained, if $R$ wins. Then, in the second period, when they know that a $D$ president is in office, they switch to 
voting $D$ for the legislature, reducing the moderation of the $D$ president. Thus $\tilde{\theta}<\tilde{\theta}_{D 2}^{*}$ cannot be an equilibrium. Analogous argument rules out $\tilde{\theta}>\tilde{\theta}_{R 2}^{*}$.

Note, from (16), that if $P_{z}=1$ (or $P_{z}=0$ ), we have $\tilde{\theta}(z)=\tilde{\theta}_{R 2}^{*}\left(\right.$ or $\tilde{\theta}(z)=\tilde{\theta}_{D 2}^{*}$ ). Thus, with no uncertainty about the presidential outcome, the legislative cutpoints are the same in both periods; as in the complete information model, we do not have (in expectation) a midterm cycle. In contrast, with uncertain presidential elections, satisfying $\left(\mathrm{C}^{2}\right)$ implies a midterm congressional cycle: the party of the president always has lower expected plurality in midterm legislative elections than in the legislative elections held at the same time as the presidential elections.

\subsection{Presidential Voting}

Let us now turn to the presidential vote. If $0<P_{z}<1$, there is a critical value of $a$ above which party $R$ wins the presidency and obtains a relatively high vote for the legislature. The expected utility of a voter is obtained by integrating out over $a$, switching from $D$ to $R$ president at the critical value. (See Appendix.) A voter will vote for $R$ for president if and only if his expected utility, $E U_{i}^{R}$, conditional on $R$ president is greater than his expected utility, $E U_{i}^{D}$, conditional on $D$ president. ${ }^{20}$ That is, a sufficient condition for domination is as follows.

Lemma 6: If $0<P_{z}<1,(S, z)$ is dominated if $\left(C^{P}\right)$ is not satisfied on $S$ :

$$
\begin{aligned}
& \text { Let } S_{R}=\left\{i: i \in S \text { and } z_{i}^{1}=R\right\} \text {. If } \sigma\left(S_{R}\right)>0, E U_{i}^{R} \geq E U_{i}^{D} \\
& \quad \text { for all } i \in S_{R} \text {. } \\
& \text { Let } S_{D}=\left\{i: i \in S \text { and } z_{i}^{1}=D\right\} \text {. If } \sigma\left(S_{D}\right)>0, E U_{i}^{R} \leq E U_{i}^{D} \\
& \quad \text { for all } i \in S_{D} \text {. }
\end{aligned}
$$

Proof: Without loss of generality, assume there exists measurable $T=\{i$ : $i \in S$ and $z_{i}^{1}=R, E U_{i}^{D}>E U_{i}^{R}$. Then, since $0<P_{z}<1$, expected utility is increased for all members of $T$ if they adopt $y_{i}^{1}=D, y_{i}^{2}=z_{i}^{2}, y_{i}^{3}=z_{i}^{3}$. Q.E.D.

Equating the two expected utilities in $\left(\mathrm{C}^{\mathrm{P}}\right)$, for $t=2$ legislative cutpoints $\tilde{\theta}_{R 2}^{*}$ and $\tilde{\theta}_{D 2}^{*}$ and arbitrary $t=1$ cutpoint $\tilde{\theta}$, we find, by use of (B-3) in the Appendix, the election cutpoint $\hat{\theta}$, as a function of $\tilde{\theta}$ :

$$
\hat{\theta}(\tilde{\theta})=\frac{\left(\theta_{D}+\theta_{R}\right)\left(\beta+(1+k)^{2}\right)+\beta k-2 k(1+k)^{2} \tilde{\theta}}{2(1+k)\left(1-k^{2}+\beta\right)}, \quad \tilde{\theta}_{D} \leq \tilde{\theta} \leq \tilde{\theta}_{R} .
$$

We now develop an important condition on the presidential strategy components given the legislative vote.

\footnotetext{
${ }^{20}$ Note that a given strategy $z$ partitions the values of $a_{1}$ such that $R(D)$ is elected president for $a_{1}$ greater (less) than a threshold value. The expectation of utility for $R(D)$ president is taken over these values.
} 
LEMMA 7: Given that the legislative components of strategies are $\tilde{\theta}, \tilde{\theta}_{D 2}^{*}, \tilde{\theta}_{R 2}^{*}, a$ necessary condition for $\left(I_{w}, z\right)$ with $0<P_{z}<1$ to be undominated by any $(T, y)$ is that the presidential component of $z$ be represented by the cutpoint $\hat{\theta}$ given by (19).

Proof: Given fixed strategy components satisfying $\tilde{\theta}, \tilde{\theta}_{R 2}^{*}$, and $\tilde{\theta}_{D 2}^{*}$, all voter types $\theta_{i}\left\{\begin{array}{l}< \\ >\end{array}\right\} \hat{\theta}$ strictly prefer $\left\{\begin{array}{l}D \\ R\end{array}\right\}$ president to $\left\{\begin{array}{l}R \\ D\end{array}\right\}$. This observation and $0<P_{z}<1$ renders the proof immediate.

Q.E.D.

When uncertainty persists $\left(0<P_{z}<1\right)$, Propositions 6 and 7 and Lemma 7 imply that $\left(I_{w}, z\right)$ is undominated only if all voters are conditionally sincere in both legislative and presidential elections.

Since $\hat{\theta}(\tilde{\theta})$ is monotone on $\left(\theta_{D}, \theta_{R}\right)$ and $\tilde{\theta}(\hat{\theta})$ is monotone on $\left(\tilde{\theta}_{D}, \tilde{\theta}_{R}\right)$, it is immediate to show that (19) and (17) have at least one solution. Because (19) is linear and (17) piecewise linear, there may be one, three, or, at a knife's edge, infinite solutions. Intuitively, if uncertainty is low, one is essentially in the complete information case, and the only stable solutions will be the exterior ones shown in panels (b) and (c) of Figure 2. If uncertainty is high, there can be a unique "mid-term cycle" $(0<P<1)$ solution illustrated by the unique intersection in panel (a).

The necessary condition for a unique interior intersection, found in the relative slopes of (17) and (19), is

$$
w>\frac{k\left(\theta_{R}-\theta_{D}-k\right)}{2\left(1-\beta-k^{2}\right)} .
$$

PROPOSITION 8: If (20) is satisfied and (17) and (19) have a solution with $0<P(\hat{\theta})<1$, an abstract stable set $\mathscr{K}^{*}=\mathscr{W} \backslash \Delta(\mathscr{B})$ exists. The unique pair of the form $\left(I_{w}, z\right)$ must have $t=2$ cutpoints $\tilde{\theta}_{R 2}^{*}$ and $\tilde{\theta}_{D 2}^{*}$ and $t=1$ cutpoints $\hat{\theta}^{*}$ and $\tilde{\theta}^{*}$, given by the unique solution of (17) and (19).

Proof: See Appendix.

REMARKS: 1. When Is the Outcome of the Presidential Election Uncertain? If $\alpha=1,(20)$ is satisfied for all $w>0$. If the president is all powerful, voters have no incentive to coordinate their votes in the first period. As the legislature's power increases and $\alpha$ falls to its minimum value of $\frac{1}{2}$, the critical value of $w$ increases. The increased incentive to coordinate means that more uncertainty in preferences is required before the presidential outcome is uncertain. Uncertain outcomes are nonetheless predicted for a wide range of parameter values. An example is shown in panel (a) of Figure 2.

2. The Midterm Cycle. If $0<P_{z}<1$, we expect a midterm cycle. Furthermore, the expected loss in midterm is higher the more unexpected was the presidential victory. The actual size of the midterm loss depends also on the realization of $a$. The probability of a reversal of the midterm loss due to the realization of $a$ is small. Indeed one can readily find parameter values for which the probability of 

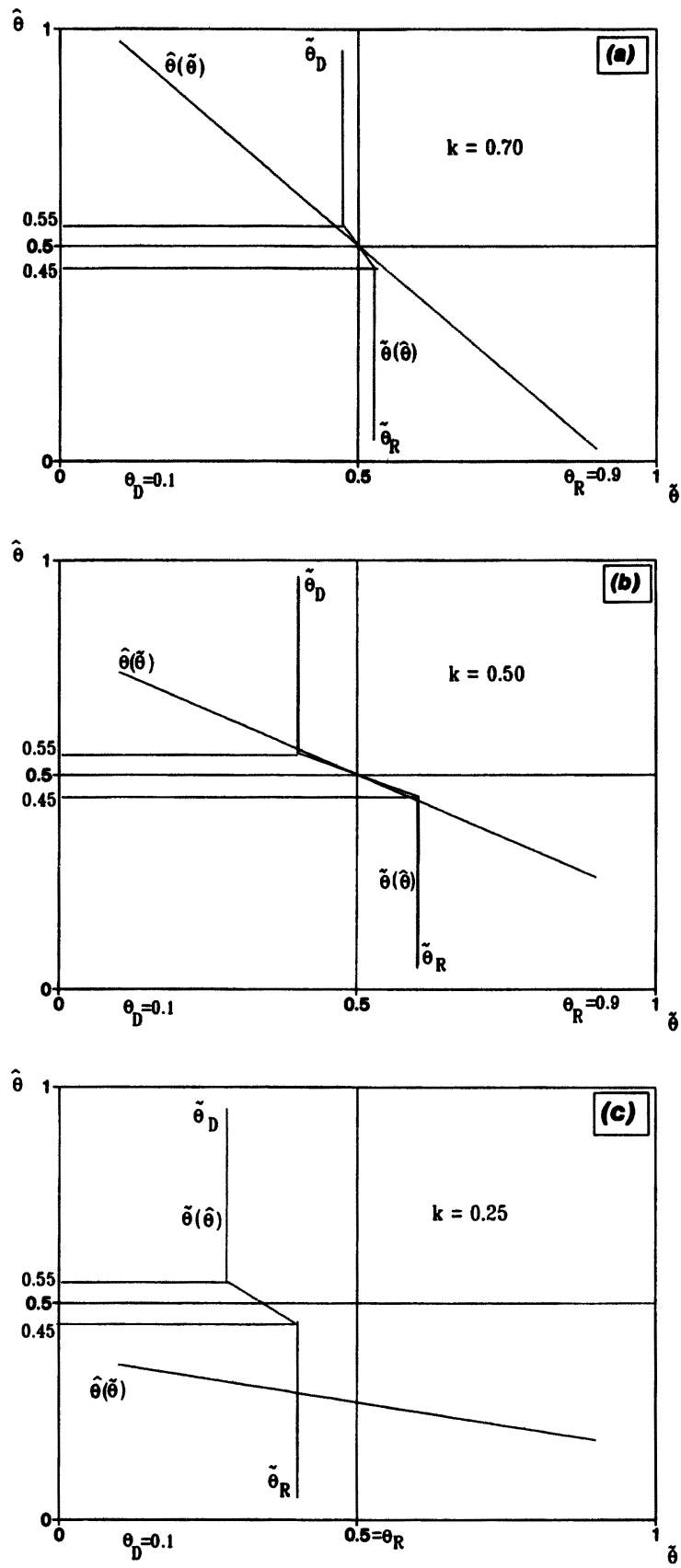

FIGURE 2.-Equilibrium under uncertainty. The $\hat{\theta}(\tilde{\theta})$ and $\tilde{\theta}(\hat{\theta})$ graphs indicate how the cutpoint for one election depends on the cutpoint for the other election. When the $\hat{\theta}(\tilde{\theta})$ line intersects a vertical segment of the $\tilde{\theta}(\hat{\theta})$ graph, the intersection represents an equilibrium for which the presidential outcome is certain. 
a reversal is 0 even though the vote in each period is subject to random variation.

3. Split-ticket Voting. If and only if $\theta_{R}+\theta_{D}=1$ is there no split-ticket voting in the first-period election. In this case only, simple algebra on (17) and (19) establishes that $\hat{\theta}^{*}=\tilde{\theta}^{*}=\frac{1}{2}$.

If $\hat{\theta}^{*}>\frac{1}{2}$, that is $P_{\hat{\theta}}^{*}<\frac{1}{2}$, the equilibrium implies three types of voters: $R R, D R, D D$. If $\hat{\theta}^{*}<\frac{1}{2}$ the three types are $R R, R D, D D$. Thus the voters who split their ticket are always a fraction of those voting for the presidential candidate more likely to win. In addition, the less uncertain is the presidential election (i.e. the larger $\left.\left|\hat{\theta}^{*}-\frac{1}{2}\right|\right)$, the larger the fraction of split tickets.

4. Divided Government. The government may be divided in both periods by split-ticket voting in period 1 or only become divided in period 2 as a result of the midterm cycle.

\section{DISCUSSION AND CONCLUSIONS}

This paper extends the spatial theory of voting to an institutional structure in which policy choices depend upon not only the executive but also the composition of the legislature. Although voting is conditionally sincere for both the legislature and the executive, voters act strategically with respect to their simultaneous choices in the two contests.

Our model has several testable implications which are consistent with some observations of voting behavior in democracies in which the executive is directly elected. With respect to the United States, for instance, the model predicts: (a) split-ticket voting; (b) for some parameter values, a divided government with different parties controlling the executive and holding a majority in the legislature; and (c) the midterm electoral cycle.

Four caveats are worth noting.

First, even though evidence of ticket splitting is widespread (Fiorina (1990)), there is also ample evidence of coattail effects, that is a successful presidential candidate helps candidates of the same party running for Congress (Calvert and Ferejohn (1983); Erikson (1990)). Our model induces coattails via the random variable $a$. For example, a high realization of $a$ corresponds to an unusually right-wing electorate that produces party $R$ successes in both presidential and congressional elections that are observationally equivalent to "coattails" outcomes. At the same time, split-tickets occur and a midterm cycle is expected, both as a result of regression to the mean in the random process and as a consequence of the systematic adjustment of legislative cutpoints.

The second caveat is the very persistence of the midterm cycle. The presidential election resolves only the uncertainty about the president's identity. In the two years between the presidential election and the midterm election, the voters acquire further information about presidential competency, personality, and policies. These additional resolutions of uncertainty could, in principle, go either way and invert the midterm cycle. But the midterm cycle persists not only in the 
presence of these other sources of information but also in those cases, such as 1964,1972 , and 1984, when there was little uncertainty about who would win the presidency.

The third caveat pertains to a variety of ways in which the structure of legislative elections in the United States differs from the national proportional representation in a unicameral legislature we used to make the model tractable. In actual practice, of course, individual legislators represent geographic constituencies in a bicameral legislature, with elections marked by considerable incumbency advantage (Fiorina (1989)). In this context, we can interpret the midterm cycle in two complementary ways. The first argues that the cycle manifests itself in "marginal" districts in which incumbents of the president's party are not reelected. The second interpretation, more directly applicable to our model, views the midterm cycle as a way in which the voters indicate their preferences by reducing the margin of victory of reelected incumbents. These smaller majorities, coupled with shifts in marginal seats, constitute a powerful signal of "moderation" which voters send to the president and members of Congress.

Fourth, the absence of policy convergence is built into our model since the positions of the parties are fixed. However, our results concerning balancing, divided government, and the midterm cycle would not disappear in a model where ideological parties can choose their positions, as in work by Wittman (1977), Calvert (1985), and Roemer (1992). ${ }^{21}$ As shown by these authors, in the absence of a legislature, presidential candidates in general choose separate positions. The introduction of a legislature leads, as we have shown, to a policy that is more moderate than the position of the president. This moderation, since it is anticipated by the parties, creates an incentive for parties to choose even less convergent platforms than those chosen without a legislature (Alesina and Rosenthal (1995, pp. 127-136).

Despite these caveats, our model makes some steps toward a more realistic characterization of the political system of the United States than the traditional "winner takes all" model developed by Hotelling, Black, and Downs. Our modeling strategy was also stimulated by the observation that the political systems of other nations are even more remote from the standard two-party competitive model. First, in parliamentary democracies, relative shares of votes generally matter for policy outcomes. Second, various institutions which lead to some sort of "checks and balances" are common, even beyond presidential systems such as the United States, France, and Venezuela. For example, many federal systems leave significant policy-making powers in the hands of provincial, regional, or local government units. In such cases it would be possible to balance, at least partially, a, say, right-wing national government with left-wing

${ }^{21}$ If parties are only electorally motivated, our model would be uninteresting since, even with our institutional structure, electoralist parties would converge to the median. 
administrations at lower levels. The basic logic of our model provides a stepping stone toward the analysis of institutional setups richer than the traditional two-party model.

\title{
Dept. of Economics, Harvard University, Cambridge, MA 02138, U.S.A. and
} Dept. of Politics, Princeton University, Princeton, NJ 08544, U.S.A.

Manuscript received October, 1989; final revision received October, 1995.

\begin{abstract}
APPENDIX
In the text, we proved that $\mathscr{K}=\mathscr{W} \backslash \mathscr{B}$ for the case of one period, complete information, and tied presidential races awarded to one party, e.g. $P_{z}=1$ if $M_{R z}=\frac{1}{2}$. The generalization to $0 \leq P_{z} \leq 1$ is covered in Alesina and Rosenthal (1993). In Section A, we generalize the proof to the two-period model with $P_{z}=1$ if $M_{R z}=\frac{1}{2}$. In Section B, we treat the two-period model with incomplete information using specific functional forms.

As a preliminary, we discuss why mixed strategies need not be considered. It is immediate to show that $(S, z)$ is dominated by some $(T, y) \in B$ for any $z$ with measurable mixed legislative components on $S$. Similarly, assume there is $(S, z)$ where $S$ contains voters who, conditional on the legislative components, prefer $R$ to $D$ for president and are mixing on the presidential component. If they can increase the probability of election of their preferred party, the mixing is dominated by a $(T, y) \in B$. A similar statement would apply to those who prefer $D$ to $R$. Moreover, if $(S, z)<(T, y)$ and $(T, y)$ involves mixing, $(S, z)<\left(T, y^{\prime}\right)$, where $y^{\prime}$ uses pure strategies on $T$. Consequently, the only mixing that would be in $\mathscr{K}=\mathscr{W} \backslash \mathscr{B}$ would be nonpiwotal mixing in presidential components. Such mixed strategies would not affect the policy outcomes associated with $\mathscr{K}$. Therefore, allowing for mixed strategies would not alter our substantive conclusions.
\end{abstract}

\section{A. The Two-Period Model with $P_{z}=1$ if $M_{R z}=\frac{1}{2}$}

The proof requires two assumptions that restrict the institutional structure and preferences considered in the one-period model.

B1. We assume that for all $z, y, x_{z}^{R t} \geq x_{y}^{D t}, t=1,2$.

This assumption says that the president's power is always at least as great as the legislature's. For (2") and (3"), B1 is equivalent to $\alpha \geq \frac{1}{2}$.

B2. Single-Crossing Property (SCP). Let $\left(x^{1}, x^{2}\right)$ and $\left(x^{1^{\prime}}, x^{2^{\prime}}\right)$ be alternative two-period policies. We assume that either one policy pair is preferred by all voters or there is a unique indifferent type $\theta$ with opposite preferences on opposite sides of $\theta$.

Define $V_{R z}^{1}$ as the first-period legislative vote for $R, V_{R}^{1 i J_{z}}$ as the first-period legislative vote bliss point for voter $i$ given the presidential outcome under $z, V_{R z}^{2 j}$ as the second-period legislative vote for $R$ in the second-period subgame corresponding to $j$ president, and $V_{R}^{2 i j}$ as the second-period legislative vote bliss point for voter $i$ in the subgame. 
Proposition A-1: Necessary and sufficient conditions for $(S, z)$ to be undominated by any $(T, y)$ where $y^{1}=z^{1}$ are

$$
z^{2} \text { ( first-period legislative component) be represented on } S \text { by a cutpoint } \tilde{\theta}_{z} \text { satisfying }
$$

$$
V_{R z}^{1}\left\{\begin{array}{l}
> \\
= \\
<
\end{array}\right\} V_{R}^{1 i J_{z}} \text { if } \quad \theta_{i}\left\{\begin{array}{c}
< \\
= \\
>
\end{array}\right\} \tilde{\theta}_{z} ;
$$

$\left(C^{2}\right) \quad z^{3}$ (second-period legislative component) be represented on $S$ by two cutpoints $\tilde{\theta}_{j z}, j=D, R$, satisfying:

$$
V_{R z}^{2 j}\left\{\begin{array}{l}
> \\
= \\
<
\end{array}\right\} V_{R}^{2 i j} \text { if } \quad \theta_{i}\left\{\begin{array}{c}
< \\
= \\
>
\end{array}\right\} \tilde{\theta}_{j z} .
$$

Proof: Directly parallel to Proposition 1 in the text.

Note that the "subgame" part of the definition of dominance prevents domination via adjustment of legislative cutpoints if $\mathrm{C}^{1}$ and $\mathrm{C}^{2}$ are satisfied.

The definition of $S$ pivotal is the same as in the one-period model in the text. Lemmas and propositions are numbered to correspond to lemmas in the text.

LEMma A-2 (No Flip-Flops): If $(S, z)<(T, y)$ where $(S, z)$ and $(T, y)$ satisfy $C^{1}$ and $C^{2}$ and $J_{z}=R$ and $J_{y}=D$, there does not exist $\left(T^{\prime}, y^{\prime}\right)$ that satisfies $C^{1}$ and $C^{2}$ such that $(T, y)<\left(T^{\prime}, y^{\prime}\right)$ and $J_{y^{\prime}}=R$.

Proof: 1. $\mathrm{C}^{2}$ satisfied implies $x_{z}^{2}=x_{y^{\prime}}^{2}$.

2. $C^{1}$ satisfied, (5) in the text, and $T^{\prime} \subset T \subset S$ imply $x_{y}^{1 R}>x_{y^{\prime}}^{1 R} \geq x_{z}^{1 R}$, where, for example, $x_{y}^{1 R}$ represents the policy were $R$ elected president with the $y$ first-period legislative vote.

3. B1 and B2 imply $T \subset\left[0, \theta_{y z}\right)$ where $\theta_{y z}$ is the voter type indifferent between the $y$ policies and the $z$ policies.

4. Let $\theta_{y y^{\prime}}$ denote the type indifferent between $y$ and $y^{\prime}$. Since by part $2 x_{y^{\prime}}^{1 R} \geq x_{z}^{1 R}$ and by part 1 $x_{y^{\prime}}^{2}=x_{z}^{2}, \theta_{y y^{\prime}} \geq \theta_{y z}$. This fact contradicts $T^{\prime} \subset T$.

Given that a "left" coalition must pivot against $R$ president (from step 3 of the proof of Lemma A-2), the next lemma gives the necessary and sufficient conditions for the rightmost member of that coalition to gain utility in deviating. In turn, if the rightmost member gains, all members gain, by B2.

Lemma A-3: If $J_{z}=R$ and $C^{1}$ and $C^{2}$ are satisfied on $(S, z),(S, z)$ is dominated if and only if $\exists(T, y), T \subset S$ such that

$$
J_{y}=D \text {, }
$$

$$
u\left(x_{y}^{D 1}, \theta_{\bar{T}}\right)+\beta u\left(x_{y}^{D 2}, \theta_{\bar{T}}\right) \geq u\left(x_{z}^{R 1}, \theta_{\bar{T}}\right)+\beta u\left(x_{z}^{R 2}, \theta_{\bar{T}}\right),
$$

$$
y_{i}=z_{i}, \quad i \notin T,
$$

$$
y^{3}=z^{3} \text {. }
$$

Proof: Sufficiency. By step 3 in the proof of Lemma A-2 and B2, to show that all members of $T$ are better off, it suffices to focus on voter type $\theta_{\bar{T}}$. If (ii) is satisfied and (iii) is satisfied and $T \subset S$, the conditions for dominance are satisfied. 
Necessity. Proposition A-1 and (C) satisfied imply that (i) is necessary. The definition of dominance implies that (iii) is necessary. Since all members of $T$ must be better off under $y$ than under $z$, (ii) is necessary. Condition (iv) is necessary by the dynamic consistency requirement for dominance given in the text.

Q.E.D.

Proposition A-3-The Abstract Core: Similar to the one-period model.

Proposition A-4-CPN Equilibria: There is a unique abstract stable set $(C P N) \mathscr{K}^{*}=\mathscr{W} \backslash \Delta(\mathscr{B})$ that contains at least one CPN pair $(I, z)$. If $(I, z) \in \mathscr{K}^{*}$, either party $R$ wins the Presidency and $\tilde{\theta}_{R}$ is the outcome in both periods or $D$ wins the Presidency and $\tilde{\theta}_{D}$ is the outcome in both periods.

PRoof: External stability, uniqueness, and $(I, z)$ in the CPN are directly parallel to the proof of Proposition 4 in the text.

Internal Stability: If $(S, z) \in \mathscr{B}$, it is undominated.

Therefore consider $(S, z) \in \mathscr{K}^{*}$ but $(S, z) \notin \mathscr{B}$. Assume $(S, z)<(T, y)$ and $(T, y) \in \mathscr{K}^{*}$. Since $C^{1}$ and $\mathrm{C}^{2}$ are satisfied on $S, J_{y} \neq J_{z}$. If $(T, y) \in \mathscr{K}^{*},(T, y)$ satisfies $\mathrm{C}^{1}$ and $\mathrm{C}^{2}$. Moreover, by Lemma A-2, no $T^{\prime} \subset T$ can gain by pivoting back to $J_{z}$. Hence $(T, y) \in \mathscr{B}$. But then $(S, z)<(T, y) \Rightarrow(S, z)$ $\notin \mathscr{H}^{*}$. Contradiction.

Hence, all $(S, z) \in \mathscr{W} / \Delta(\mathscr{B})$ are internally stable.

Q.E.D.

\section{B. The Incomplete Information Model}

We maintain the definition of dominance used in the two-period model with complete information. We also maintain B1. SCP is implied by quadratic utility.

We begin by generalizing the $\left(C^{P}\right)$ condition in the text to $0 \leq P_{z} \leq 1$. Let $\sigma_{a}(S)$ denote the measure of $S$ conditional on the realization of $a$.

$\left(C^{\mathrm{P}}\right) \quad(S, z)$ is dominated if not for all $i \in S$ :

$$
\text { if } 0<P_{z}<1 \text {, }
$$

identical to text;

if $P_{z}=0$,

$$
\min _{a \in[-w,+w]} \sigma_{a}\left(\left\{i \in S, z_{\imath}^{1}=D \text { and } E U_{i}^{R}<E U_{i}^{D}\right\}\right)+\sigma_{a}\left(\left\{i \in I \backslash S \text { and } z_{i}^{1}=D\right\}\right)>\frac{1}{2} ;
$$

if $P_{z}=1$,

$$
\min _{a \in[-w,+w]} \sigma_{a}\left(\left\{i \in S, z_{i}^{1}=R \text { and } E U_{i}^{R}>E U_{i}^{D}\right\}\right)+\sigma_{a}\left(\left\{i \in I \backslash S \text { and } z_{i}^{1}=R\right\}\right)>\frac{1}{2} .
$$

Note that for any strategy $s$ such that voters at or to the left of $\theta_{D}$ always vote $D$ and at or to the right of $\theta_{R}$ always vote $R$, we can express the legislative vote for a contest as

$$
V_{R}=E V_{R}+a
$$

and the presidential vote as

$$
M_{R}=E M_{R}+a
$$

where $E$ denotes the expected vote. 
Consider, then, the expected utility for voter $i$ :

if $\frac{1}{2}-w<E M_{R}<\frac{1}{2}+w$,

$$
\begin{aligned}
E u_{i}= & -\frac{1}{2}\left\{\int _ { \frac { 1 } { 2 } - E M _ { R } } ^ { + w } \left[\left(\theta_{R}-k+k E V_{R}^{1}+K a_{1}-\theta_{i}\right)^{2}\right.\right. \\
& \left.+\beta \int_{-w}^{+w}\left(\theta_{R}-k+k e V_{R}^{2 R}+k a_{2}-\theta_{i}\right)^{2} \frac{1}{2 w} d a_{2}\right] \frac{1}{2 w} d a_{1} \\
& +\int_{-w}^{\frac{1}{2}-E M_{R}}\left[\left(\theta_{D}+k E V_{R}^{1}+k a_{1}-\theta_{i}\right)^{2}\right. \\
& \left.\left.+\beta \int_{-w}^{+w}\left(\theta_{D}+k E V_{R}^{2 D}+k a_{2}-\theta_{i}\right)^{2} \frac{1}{2 w} d a_{2}\right] \frac{1}{2 w} d a_{1}\right\} \\
= & -\frac{1}{2}\left\{\frac{w-\frac{1}{2}+E M_{R}}{2 w}\left[\left(\theta_{R}-k+k E V_{R}^{1}-\theta_{i}\right)^{2}+\beta\left(\theta_{R}-k+k E V_{R}^{2 R}-\theta_{i}\right)^{2}\right]\right. \\
& +\frac{w+\frac{1}{2}-E M_{R}}{2 w}\left[\left(\theta_{D}+k E V_{R}^{1}-\theta_{i}\right)^{2}+\beta\left(\theta_{D}+k E V_{R}^{2 D}-\theta_{i}\right)^{2}\right] \\
& \left.+\frac{1}{2 w}\left(w^{2}-\left(\frac{1}{2}-E M_{R}\right)^{2}\right)\left(\theta_{R}-\theta_{D}-k\right)+\frac{k^{2} w^{2}(1+\beta)}{3}\right\}
\end{aligned}
$$

and where the notation " $2 R$ " and " $2 D$ " denotes that the expected second-period vote will depend on the outcome of the presidential election.

It can be seen that (B-3) is a function solely of the parameters of the model, the voter's ideal point, and the expected votes for the various contests, and is quadratic in the expected votes.

Proof of Proposition 6: 1 . It is immediate to show that $(S, z)$ undominated implies that for all $i \in S \cap\left[-w, \theta_{D}\right], z_{l}^{3}=D$ and for all $i \in S \cap\left[\theta_{R}, 1+w\right], z_{i}^{3}=R$.

2. Since (B-3) is quadratic, Proposition 6 then follows by arguments directly parallel to the proofs of Propositions 1 and 2.

Q.E.D.

Proof of Lemma 5: Equation (16) follows directly from (B-3) and $a$ uniform by substituting using $P_{z}=\left(w-\frac{1}{2}+E M_{R}\right) / 2 w$. Equation (17) then follows directly from (16).

Lemma B-2 (No Flip-Flops): If $(S, z)<(T, y)$ where $(S, z)$ and $(T, y)$ satisfy $C^{1}$ and $C^{2}$ and $C^{P}$ and $P_{y}<P_{z}$, there does not exist $\left(T^{\prime}, y^{\prime}\right)$ that satisfies $C^{1}$ and $C^{2}$ and $C^{P}$ such that $(T, y)<\left(T^{\prime}, y^{\prime}\right)$ and $P_{y^{\prime}}>P_{y}$.

Proof: 1. First consider $S=I$. In this case, $\mathrm{C}^{1}$ and $\mathrm{C}^{\mathrm{P}}$ satisfied permit substitution of $\hat{\theta}=1-$ $E M_{R}$ and $\tilde{\theta}=1-E V_{R}^{1}$ in (B-3). Use (17) to eliminate $\tilde{\theta}$ from (B-3). Routine differentiation and simplification then shows that given $\mathrm{B} 1$ and $\mathrm{C}^{\mathrm{P}}$ :

$$
\frac{d E u_{i}}{d \hat{\theta}}\left\{\begin{array}{l}
\geq \\
= \\
\leq
\end{array}\right\} 0 \quad \text { if } \quad \theta_{i}\left\{\begin{array}{c}
< \\
= \\
>
\end{array}\right\} \hat{\theta} .
$$

(In other words, if $P_{y}<P_{z}$ and $(I, z)<(T, y)$ with $\mathrm{C}$ conditions satisfied, individuals at the left-end of the policy space ( $i=-w$, for example) must be better off. This and SCP establish that $S$ must be a left coalition.)

2. The same can be shown for $S \subset I$, except that the vote and cutpoint expressions must be adjusted for the strategies of voters in $I \backslash S$. The weak inequalities in (B-4) allow not only for $P=0$ and $P=1$ but also for the fact that $S \subset I$ is not restricted to being a connected set. 
3. Now assume $P_{y^{\prime}}>P_{y}$. Equation (B-4) implies that $\theta_{\bar{T}}$ prefers $y$ to any $y^{\prime}$ that satisfies $\mathrm{C}^{1}$ and $\mathrm{C}^{2}$ on $T^{\prime}$.

4. Moreover, if $\theta_{\bar{T}}$ does better than under $y$ with any $y^{\prime}$ with $P_{y^{\prime}}>P_{y}$ that satisfies $\mathrm{C}^{1}$ and $\mathrm{C}^{2}$ on $T^{\prime} \subset T$, the first-period legislative cutpoint for $T^{\prime}$ and $P_{y^{\prime}}$ must be greater than the cutpoint for $T$ and $P_{y^{\prime}}$. But this contradicts $T^{\prime} \subset T$ and $\mathrm{C}^{1}$ and $\mathrm{C}^{2}$ satisfied.

5. Since the utility of $\theta_{\bar{T}}$ cannot be improved with $P_{y^{\prime}}>P_{y},(T, y)<\left(T^{\prime}, y^{\prime}\right)$ cannot be satisfied.

Q.E.D.

Proof of Proposition 8: Uniqueness and external stability have identical arguments as in the complete information case.

Internal Stability: Internal stability also obviously holds for $(S, z) \in \mathscr{B}$.

Consider $(S, \dot{z}) \in \mathscr{K}, \mathrm{C}^{1}, \mathrm{C}^{2}$, and $\mathrm{C}^{\mathrm{P}}$ satisfied but $(S, z) \notin \mathscr{B}$.

W.l.o.g. assume $(S, z)<(T, y), P_{y}<P_{z}$, and $\mathrm{C}^{1}, \mathrm{C}^{2}$, and $\mathrm{C}^{\mathrm{P}}$ satisfied for $(T, y)$.

1. Lemma B-2 implies that there does not exist $\left(T^{\prime}, y^{\prime}\right) \in \mathscr{K}$ such that $(T, y)<\left(T^{\prime}, y^{\prime}\right)$ and $P_{y^{\prime}}>P_{y}$.

2. Therefore assume $P_{y^{\prime}}<P_{y}$. If $(S, z)<(T, y)$ and $(T, y)<\left(T^{\prime}, y^{\prime}\right)$, it follows that all $i \in T$ prefer $y^{\prime}$ to $z$. Moreover, $\mathrm{C}^{1}, \mathrm{C}^{2}$, and $\mathrm{C}^{\mathrm{P}}$ satisfied imply that $z, y$, and $y^{\prime}$ are cutpoint on $S, T$, and $T^{\prime}$ respectively with $\hat{\theta}_{y^{\prime}}<\hat{\theta}_{y}<\hat{\theta}_{z}$ and $\tilde{\theta}_{y^{\prime}}>\tilde{\theta}_{y}>\tilde{\theta}_{z}$. It follows that if $T^{\prime}$ is able to dominate $y$ with $y^{\prime}$ it is also able to dominate $z$ using $y^{\prime}$ in $T^{\prime}$. Hence $(S, z)<\left(T^{\prime}, y^{\prime}\right)$. Consider then, of all $(T, y)$ that dominate $(S, z)$ and satisfy $\mathrm{C}^{1}, \mathrm{C}^{2}$, and $\mathrm{C}^{\mathrm{P}}$, the pair with the minimal value of $P_{y}$. This pair must belong to $\mathscr{B}$. We have shown a contradiction, $(S, z) \notin \mathscr{K}$.

$\left(I_{w}, z\right)$ in $\mathscr{K}$. Equations (17), (19), and (20) are satisfied by assumption, with $0<P<1$. Thus, there is a unique $\left(I_{w}, z\right)$ which could possibly be in $\mathscr{K}$. It is represented by the four cutpoints $\hat{\theta}^{*}, \tilde{\theta}^{*}, \tilde{\theta}^{R 2^{*}}, \tilde{\theta}^{D 2^{*}}$. We must show that $\left(I_{w}, z\right)$ is undominated by any $(S, y) \in \mathscr{B}$. Such $(S, y)$ must keep the second-period strategies constant and change (in $S$ ) both first-period cutpoints.

Without loss of generality, assume $\hat{\theta}^{*} \geq \tilde{\theta}^{*}$.

Consider a deviation that can be represented by $\hat{\theta}_{y}>\hat{\theta}^{*}$. Since the type at $\hat{\theta}_{y}$ has a strict preference for a $R$ president at $\hat{\theta}^{*}, \tilde{\theta}^{*}$, this type cannot be better off at $\hat{\theta}_{y}$ unless there is a change in the first-period legislative vote of the form $\tilde{\theta}_{y}<\tilde{\theta}^{*}$. The $\mathrm{C}^{1}$ condition can be met by a deviating coalition $S=\left[\tilde{\theta}_{y}, \hat{\theta}_{y}\right]$ as long as $\tilde{\theta}_{y}>\tilde{\theta}\left(\hat{\theta}_{y}\right)$ given by (17). For all such $\tilde{\theta}_{y},(20)$ guarantees that, in (19), $\hat{\theta}\left(\tilde{\theta}_{y}\right)<\hat{\theta}_{y}$, which implies that $C^{\mathrm{P}}$ is not satisfied on $S$. A similar argument applies to $\hat{\theta}_{y}<\hat{\theta}^{*}$. Hence, $\left(I_{w}, z\right)$ is undominated by an element of $\mathscr{B}$, implying $\left(I_{w}, z\right) \in \mathscr{K}$.

Q.E.D.

\section{REFERENCES}

Alesina, A. (1988): "Credibility and Policy Convergence in a Two-Party System with Rational Voters," American Economic Review, 78, 796-806.

Alesina, A., AND H. Rosenthal (1989): "Partisan Cycles in Congressional Elections and the Macroeconomy," American Political Science Review, 83, 373-398.

- (1993): “A Theory of Divided Government," Mimeo, Harvard University.

(1995): Partisan Politics, Divided Government, and the Economy. New York: Cambridge University Press.

Alesina, A., J. Londregan, And H. Rosenthal (1993): "A Model of the Political Economy of the United States," American Political Science Review, 87, 12-33.

$\rightarrow$ Bernheim, D., B. Peleg, And M. Whinston (1987): "Coalition Proof Nash Equilibria. 1. Concepts," Journal of Economic Theory, 42, 1-12.

Calvert, R. (1995): "Robustness of the Multidimensional Voting Model, Candidate Motivations, Uncertainty and Convergence," American Journal of Political Science, 29, 69-95.

Calvert, R., And J. A. Ferejohn (1983): "Coattail Voting in Recent Presidential Elections," American Political Science Review, 77, 407-416.

Cox, G. (1987): The Efficient Secret: The Cabinet and the Development of Political Parties in Victorian England. Cambridge, U.K.: Cambridge University Press.

ENElow, J., AND M. Hinich (1984): The Spatial Theory of Voting. Cambridge, U.K.: Cambridge University Press. 
ERIKSON, R. (1988): “The Puzzle of Midterm Loss,” Journal of Politics, 50, 1012-1029.

- (1990): "Economic Conditions and the Congressional Vote: A Review of the Macrolevel Evidence," American Journal of Political Science, 34, 373-399.

FIORINA, M. (1988): "The Reagan Years: Turning to the Right or Groping Toward the Middle," in The Resurgence of Conservatism in Anglo-American Democracies, ed. by B. Cooper, et al. Durham: Duke University Press.

- (1989): Congress: Keystone of the Washington Establishment, 2nd edition. New Haven: Yale University Press.

- (1990): “An Era of Divided Government," in Developments in American Politics, ed. by B. Cain and G. Peele. Oxford: Oxford University Press.

$\rightarrow$ (1991): "Coalition Governments, Divided Governments, and Electoral Theory," Governance: An International Journal of Policy and Administration, 4, 236-249.

$\rightarrow$ Greenberg, J. (1989): "Deriving Strong and Coalition Proof Nash Equilibria from an Abstract System," Journal of Economic Theory, 49, 195-202.

(1990): The Theory of Social Situations: An Alternative Game-Theoretic Approach. Cambridge, U.K.: Cambridge University Press.

Greenberg, J., AND K. A. Shepsle (1987): “The Effect of Electoral Rewards in Multiparty Competition with Entry," American Political Science Review, 81, 525-537.

Hammond, T., AND G. Miller (1988): "The Core of the Constitution," American Political Science Review, 84, 1155-1174.

$\rightarrow$ Hinich, M., AND P. C. ORdeshook (1969): “Abstentions and Equilibrium in the Electoral Process," Public Choice, 7, 81-106.

Kramer, G. (1973): “On a Class of Equilibrium Conditions for Majority Rule,” Econometrica, 41, 285-297.

ORDESHOOK, P. C. (1986): Game Theory and Political Theory. Cambridge, U.K.: Cambridge University Press.

Poole, K. T., and H. Rosenthal (1984a): "U.S. Presidential Elections 1968-1980: A Spatial Analysis," American Journal of Political Science, 28, 283-312.

- (1984b): "The Polarization of American Politics," Journal of Politics, 46, 1061-1079. 228-278.

Roemer, J. (1992): “A Theory of Class Differentiated Politics in Electoral Democracy,” Working Paper No. 384, Dept. of Economics, University of California at Davis.

Rosenthal, H., AND S. SEN (1973): "Electoral Participation in the French Fifth Republic," American Political Science Review, 67, 29-54.

$\rightarrow$ SHEPSLE, K. A. (1986): "The Positive Theory of Legislative Institutions: An Enrichment of Social Choice and Spatial Models," Public Choice, 50, 135-178.

$\rightarrow$ WitTman, D. (1977): “Candidates with Policy Preferences: A Dynamic Model," Journal of Economic Theory, 14, 180-189.

- (1990): "Spatial Strategies When Candidates Have Policy Preferences," in Advances in the Spatial Theory of Voting, ed. by M. Hinich and J. Enelow. Cambridge, U.K.: Cambridge University Press, 66-98. 